PUTTING THE COMMUNITY IN COMMUNITY SCHOOLS

A Dissertation submitted to the faculty of

As

35

2016

EDD

- 155
San Francisco State University

In partial fulfillment of

the requirements for

the Degree

Doctor of Education

In

Educational Leadership

by

Carol R. Hill

San Francisco, California

January 2016 
Copyright by Carol R. Hill 2016 


\section{CERTIFICATION OF APPROVAL}

I certify that I have read Putting the Community in Community Schools by Carol R. Hill, and that in my opinion this work meets the criteria for approving a dissertation submitted in partial fulfillment of the requirement for the degree Doctor of Education in Educational Leadership at San Francisco State University

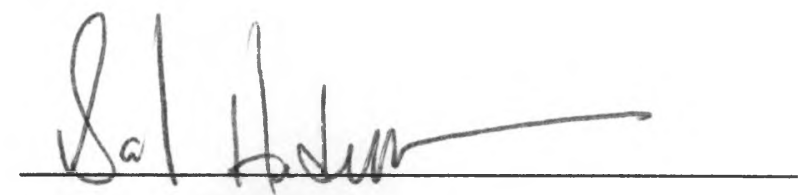

Barbara Henderson, Ph.D.

Professor
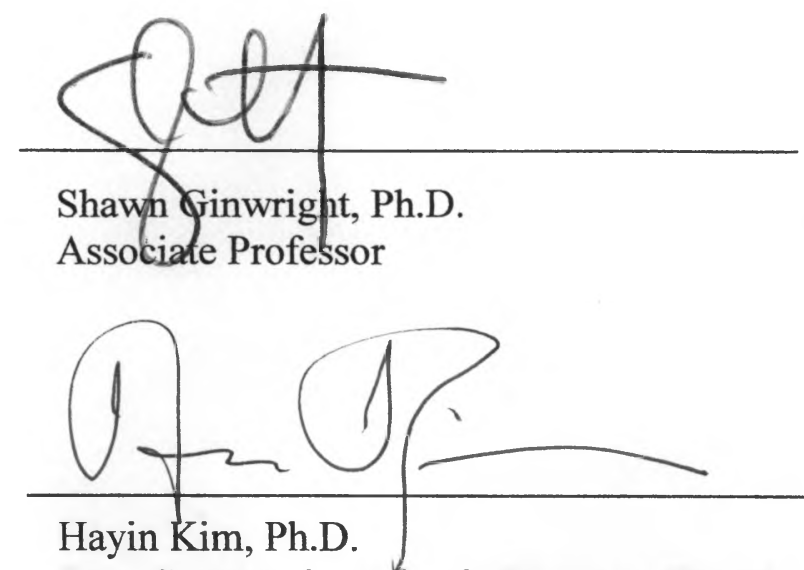

Fmr. Community Schools Director, SFUSD 


\title{
PUTTING THE COMMUNITY IN COMMUNITY SCHOOLS
}

\author{
Carol R. Hill \\ San Francisco, California \\ 2016
}

This three-paper study examines the equitable integration of community based organization representation in leadership structures in SFUSD schools implementing the community schools model. Paper 1 explores the context for community schools strategy implementation in San Francisco public schools. It includes a brief history of local community schools work, particularly highlighting the partnership with Beacon Centers, a known prototype for successful school-community collaboration. Additionally, it details the concepts of shared leadership, the equitable integration of community based organization (CBO) voice, as well as the impact of power dynamics on school-CBO partner collaboration. The second paper is a qualitative cross case analysis of three schools (including the researcher's site), that explores how they share leadership and integrate community based organization (CBO) representation in leadership structures within those community schools. The schools were comprised of an elementary, middle and high school, all of which were in the process of implementing the community schools strategy. Beacon Centers were located at two of the school sites and their roles were specifically examined. Finally, the third part of the study is a policy paper that focuses on schools and $\mathrm{CBO}$ partners sharing leadership practices when implementing the community schools approach. It proposes recommendations that would facilitate and strengthen the equitable inclusion of community based organization voice in leadership structures in San Francisco community schools.

I certify that the Abstract is a correct representation of the content of this dissertation.

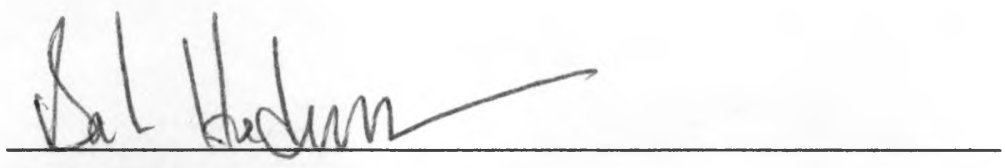

Chair, Dissertation Committee

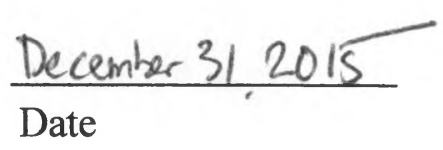




\section{ACKNOWLEDGMENTS}

I would like to acknowledge and thank the following people, without whom this dissertation would have remained unfinished forever.

Dr. Barbara Henderson for constantly encouraging me to keep moving toward the finish line. Her tireless generosity, patience and guidance were instrumental in the completion of this work;

Drs. Shawn Ginwright and Hayin Kim, my dedicated committee members, who shared their expertise and feedback graciously, and believed in me and my work;

Pam Pradachith-Demler of the San Francisco Beacon Initiative for the generous contribution toward the completion of this dissertation;

Drs. Armineh Noravian, Diana Balgas, and Jeanine Hawk, and the rest of Cohort 2011, who made this crazy experience fun and deeply rewarding. We began as cohort-mates and leave as friends;

All my family and friends, particularly my wife, Karen, who held it down for the last two years, especially, while I slugged through. And my kiddies, Isiah (born during first semester finals) and Ariel, I have no bigger inspiration.

Finally, to practitioners and educators everywhere, may this work help you collaborate and lead together with ease and purpose, as we all understand that "we cannot do it alone." 


\section{TABLE OF CONTENTS}

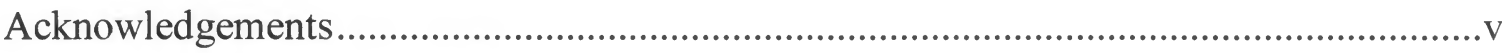

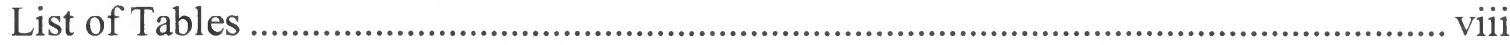

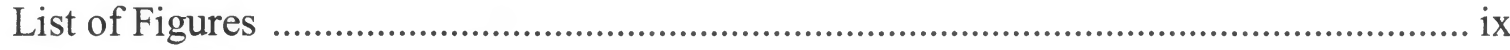

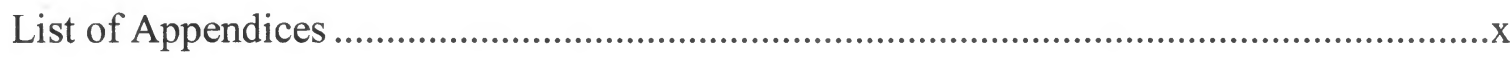

Paper One: The Distinct Context and Opportunity for the Community Schools Efforts in

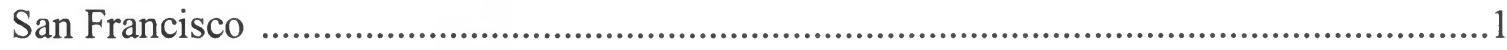

Community Schools Model in San Francisco...................................................9

Community Schools Model and Beacons .................................................... 14

Collective Impact ...................................................................................20

Equitable Integration of CBO Voice........................................................ 31

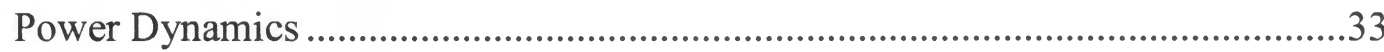

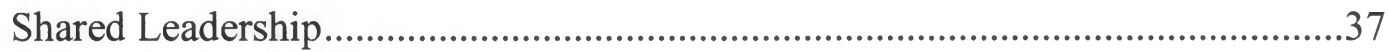

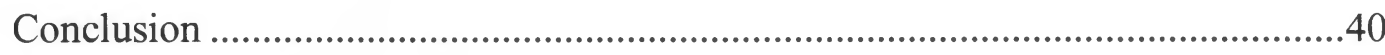

Paper Two: A Comparative Case Study ..............................................................4 47

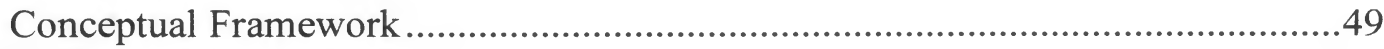

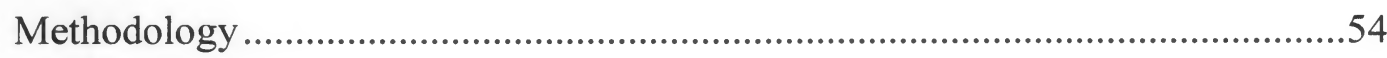

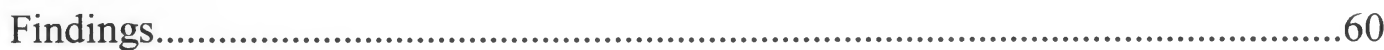

Cross Case Comparisons........................................................................68

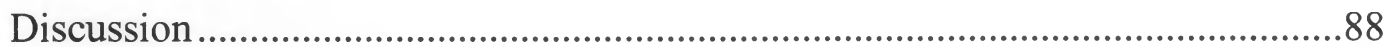

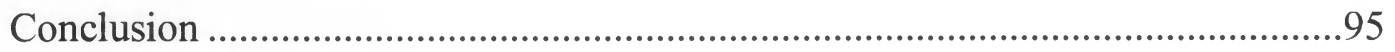


Paper Three: Equitable Integration of Community Based Organizations' Voices ........101

Summary of Papers ..............................................................................................106

Shared Leadership in Community Schools Strategy .............................................113

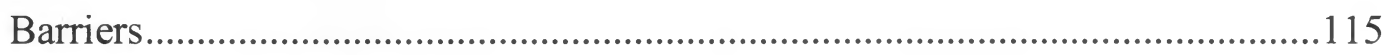

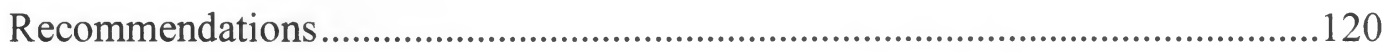

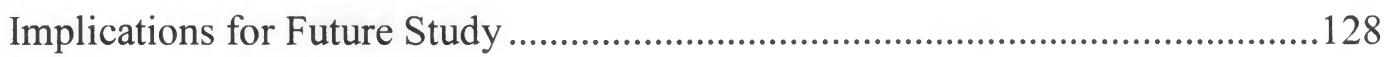

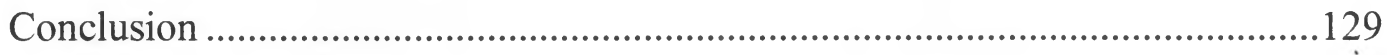

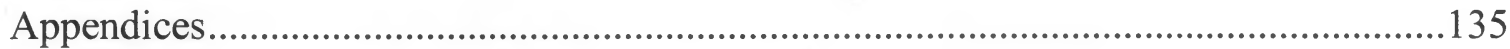




\section{LIST OF TABLES}

Table

Page

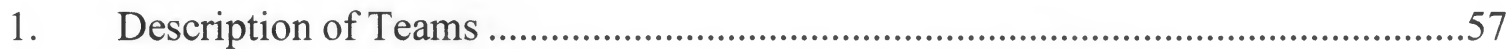

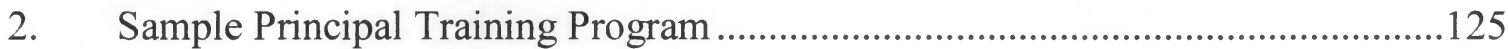




\section{LIST OF FIGURES}

Figure

Page

1. Equitable Integration of CBO Voice in Leadership Structures Theory

134 


\section{LIST OF APPENDICES}

Appendix

Page

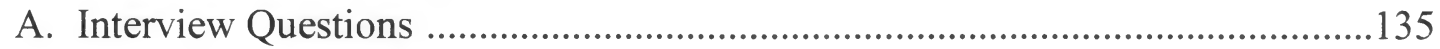

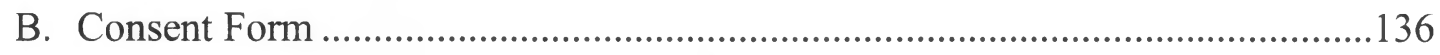




\section{Paper 1 \\ Beacon Centers, Collective Impact, \& Shared Leadership: \\ The Distinct Context and Opportunity for the Community Schools Efforts in San Francisco}

\section{Introduction}

Just before I began a doctoral program in Educational Leadership at San

Francisco State University in 2011, I had published an article where I shared my account of the wondrous and often difficult process of implementing the community schools

model between my Beacon Center and the high school we partnered with (Hill, 2011). Initially, the article served two purposes: 1) it satisfied the writing requirement for the National Institute for Out-Of-School Time (NIOST) program, an out of school time (OST) practitioner/scholar fellowship that I had received, and 2) it gave me an outlet to discuss the rewarding, yet simultaneously frustrating, process of changing the way that a school and a community based organization $(\mathrm{CBO})$ work together. My thesis was that as schools and nonprofit programs deepen their alignment and tighten partnerships under the community schools model, they would also have to find a way to share leadership and power. Publishing the article and finishing the fellowship should have been the end of the story, but to my surprise, it was just the beginning.

What started as a requirement and a way of releasing frustration became a source of empowerment and hope for other community based organization (CBO) partners engaged in similar processes of building deeper collaboration with schools. It seemed that I had tapped into an issue that did not often have a platform for discussion, namely the school-community partnership from the perspective of the non-school entity. My colleagues from around the nation, both school and CBO affiliated alike, expressed their 
appreciation of my viewpoint on the topic. All the attention elucidated the fact that there was a real need for more information on the issue of school-nonprofit partnering, as well as on the factors that might facilitate more productive and successful relationships. Additionally, I had noticed that Beacons were often mentioned in the national discourse on community schools at conferences. Indeed, Beacons have a history of providing foundational examples of successful school and community partnering. At the same time, Beacons' role in San Francisco Unified School District's (SFUSD) current community schools approach was not as clear. To take one major example, School Improvement Grant (SIG) funding supported hiring community schools coordinator as district employees, not Beacon directors, whọ are employed by community-based organizations. Given the positive feedback to my article, the special role of Beacons (of which I am a local leader), and particular issues around implementation of community schools at SFUSD, I decided that my voice might be even more useful if I were able to use my dissertation to examine factors that strengthen school-CBO relationships.

As a result of intense study and 3 more years of professional experience, I have seen a number of recurring issues. First, I often hear or read that the community schools model is about leveraging resources and collaborating across organizations and institutions. However, I hardly ever find particulars about how that should be accomplished, best practices to maximize opportunities, or paths that avoid pitfalls. A second related issue is how the organizations build trust. Trust is important in any collaborative relationship; however, its cultivation is not often prioritized. This trust is a key ingredient to building the types of links between CBOs and staff at the school site or district level that would lead to long-term, productive, and durable connections. Tightly 
braided partnerships are necessary to weather the inevitable ups and downs of the process of solving educational problems. A third challenge to school-CBO partnerships is that people expect results quickly, yet the community schools strategy takes quite some time to work through the formation stages, before it can provide replicable results. Finally, as schools implement the community schools model, building stronger connections, blending resources and forging more mutually beneficial partnerships with CBOs, it is important that leadership is shared equitably between districts and CBOs.

A simple definition of what I mean by sharing leadership equitably is similar to the "equitable integration of $\mathrm{CBO}$ voice" is the fair inclusion of nonprofit partner input in school decision-making processes. This might look different across a range of schools. Some CBOs might participate on all of the school's top admin teams, as I did at Burton High School, the school that partnered with my Beacon Center. Others might be comfortable with more informal ways of giving and receiving input for decisions. Some CBOs might have input on all decisions for the school. Others might have input only on decisions that relate to support services.

The word equitable, as opposed to equal, means the integration of the $\mathrm{CBO}$ input merely has to be what is appropriate for the partners to feel connected and invested in the agreed upon goals of the school, and the school to feel connected and invested in the priorities of its partners. What is needed would ideally be determined in the prework that is necessary in cross sector collaborations. School staff and partners would convene to discuss how, when and which avenues, and which kinds of decisions would make sense for the $\mathrm{CBO}$ partner to give and receive input on, given the mandates of the school and the CBO partners' own obligations and capacity. When partners make the effort to 
ensure equitable integration of $\mathrm{CBO}$ voice, it is the operationalization of the commitment to proceed as a unit, versus alone.

When schools and CBOs address complex problems by developing partnerships that equitably integrate $\mathrm{CBO}$ voice in decision-making processes, this shift in the way of doing business is major. It is a shift that will enable stronger, more committed collaborations that could result in solving a deeply rooted educational problem, such as eliminating the achievement gap for African Americans. Guiding my study is the research question: How do San Francisco Unified School District community schools, including those operating with and without Beacon Centers, equitably integrate their community based organizations (CBOs) into the leadership structure of their community schools team? I will explore some of the aforementioned issues in the context of the rich and complicated partnerships at play in San Francisco's community schools terrain, as well as the literature around the facilitative factors for implementing a partnership strategy. Specifically, this paper will ground the reader with background information including a description of who I am and what role I play, the community schools model and its evolution as a strategy for San Francisco Unified School District (SFUSD), and finally, an examination of the role of Beacons within the community schools strategy, as Beacons are one of the most under-researched foundational models for the community schools approach. This paper will also examine key factors that help support the equitable integration of community based organization representation in leadership structures for schools implementing a community schools approach, such as the role of power dynamics in shared leadership practices. The interplay among the Beacon Centers, SFUSD, and my school site will serve as the context in which to potentially locate the 
elements needed for a fruitful collaborative process within the framework of the community schools model. Figure 1 is a graphic representation of how the elements function together. My hope is that, although this information is based out of San Francisco, that the findings will be valuable to the entire field.

\section{The Problem --Schools Can't Do it Alone}

Public schools play an important role in communities: they are funded by the government to educate the next generation. This is an enormous responsibility and task, given the numerous constraints that have to be factored in. For example, at any given time, and often without an increase of support, schools and school districts are accountable to the government and communities to carry out several mandates and initiatives, such as No Child Left Behind and Common Core Standards, with the ultimate goal of strengthening students' academic performance. Additionally, because schools are publicly funded, their resources are often tightly prescribed. They generally do not have very much freedom to be creative in their spending practices. Therefore, because the main focus of a school is academic performance, most of their resources support a traditional understanding of teaching and learning.

At the same time, our grasp of what urban students need in order to be successful has changed dramatically. In particular, schools have had to adjust to students who have had to navigate a number of barriers before they even enter the classroom. These obstacles may include the effects of poverty, hunger, and community violence. Some of their families are suffering from the impact of homelessness, unemployment, substance abuse, and incarceration. What do these external issues have to do with schools? 
Everything. These issues impede students' readiness to learn and often greatly contribute a negative impact on their academic performance.

In San Francisco, for example, the situation for African American students illustrates the dilemma facing public schools. San Francisco Unified School District (SFUSD) maintained an overall 82 percent graduation rate for the 2013-14 school year. However, the graduation rate for African American students was in the mid 60's, where it has hovered for several years. In addition, SFUSD successfully decreased total suspensions by half over a three-year period. However, African American students were still disproportionately represented among the population of students who were suspended. The issues of lower graduation rates and high suspensions for African American youth are not new. They have persisted over time in SFUSD with very little change. In light of the evidence, San Francisco, like many school districts across the country, recognized that its schools could not solve these complex and layered problems alone. They would need much more support to help move the needle for student achievement.

Many schools campuses have an often untapped or underutilized asset available to them that is similarly tasked with supporting students at school to reach their highest potential. Community based organization (CBO) partners operate on school campuses regularly, and often use their resources to focus on the whole child, including their academics, social lives and welfare, and college and career goals. Often they are a resource for parents and students to help navigate the school's systems, as well as provide linkages in such areas as housing, employment and adult education. If the $\mathrm{CBO}$ is rooted in the communities in which the students live, its staff might already have relationships 
with the students' family and be familiar with issues within the neighborhood. This familiarity frequently makes forging and strengthening relationships that support the whole student easier. Additionally, CBOs often have different funding streams, and

therefore, might have more flexibility with how to spend money to serve the students and their families.

However, while public schools and CBOs have worked together in the past, they have functioned, as separate entities, with detached yet often related goals. In my 2011 article, I likened levels of partnership to dating levels: friends with benefits, dating, and marriage. In the romantic world, I think that the devotion level of the relationship between most schools and their Beacon Centers partners, pre community schools model, could be aptly described as dating. The community schools strategy gives this relationship a framework that allows the two entities to strengthen their relationship such that they are able to tackle complex educational issues together. In my case, eventually, the principal and I became willing to make the commitment to work together toward goals that we co- created. We went from co-located separate entities, to committed partners. In other words, we got engaged (Hill, 2011).

\section{A Solution: Community Schools Model}

It is crucial that schools and communities work together to cultivate the relationship necessary to tackle complex educational issues, especially as programs and services continue to face decreased funding and priorities change. One strategy that has proven productive for several school districts around the nation highlights high-touch collaborations with community groups that support urban students' education and lives. Schools and CBO programs transform their relationship almost from landlord and tenant on school campuses, to two entities strategically aligned with a common vision and 
shared goals. This approach, which has spanned several decades, has been referred to as school-community partnerships and, more recently, as the community schools model. By either name, when this convergence is effective, it has resulted in a win-win for both school and community priorities (Blank, Melaville \& Shah, 2003; Children's Aid Society 2006; Dryfoos, 2002).

The community schools approach hinges on the belief in that often cited notion: "it takes a village." Schools and communities work together to address the barriers to learning and bolster the supports that allow children to be both good citizens and scholars. It is "a strategy for combining and organizing resources of the school and community around student success." (Quinn, 2012). It is a strategy is predicated on the notion that schools producing thriving students often feature focused and engaged connections among and between school and community members. These groups include staff and students, as well as any group that also plays an important role in the lives of students. Stakeholders include: institutions of higher learning, local residents, business owners, parents, faith based organizations, community based organizations (CBOs), and government officials. Coupling a responsive instructional core in the classroom with meaningful community engagement outside of school has resulted in positive outcomes for urban youth and their communities. Higher graduation and attendance rates and lower rates of truancy and suspensions are just a few benefits of the community schools model (Coalition for Community Schools, 2006; Children's Aid Society 2006; Dryfoos, 2000). The community schools model helps facilitate school and CBO collaboration. Partnering between these two types of entities is an example of cross sector collaboration:

\footnotetext{
${ }^{1}$ Quote has been referenced as an African proverb. Several African languages have proverbs that are similar so it is difficult to definitively attribute the saying to anyone.
} 
a government sector agency with an independent. Understanding the nature of the community schools approach is essential to grasp the depth of commitment the school and community organization need to make. Yet how the schools should include CBO representation in decision-making processes of leadership structures is non-obvious. Therefore, school and CBO leaders need more knowledge of cross sector collaboration and what connections it might facilitate to better integrate $\mathrm{CBO}$ voice into leadership structures. The following sections will describe how San Francisco has been implementing the community schools model, the challenges SFUSD has faced with cross-sector collaboration, and what role Beacon Centers play.

\section{The Community Schools Model in San Francisco}

"In San Francisco we ask how we are going to improve educational outcomes for our most disenfranchised children. We find folks who can help us do this work and coordinate the pieces so that all students have a shot at being successful."

Richard Carranza --Superintendent, SFUSD, 2011

As was the case for many districts, SFUSD decided to implement the community schools approach when it recognized that it could not reach the city's public educational goals alone. This section gives a brief history of the San Francisco community schools movement. It is an example of how one district came to adopt the community schools model, and how it evolved over a few years,

While there was encouraging news for Burton High School and SFUSD from the 2011-12 school year, the years before were not as promising. Many of San Francisco's children, particularly Black and Latino students, were failing (SFUSD, 2011). Concurrently, California had experienced significant funding reductions in education. In order to balance the budget, SFUSD pink-slipped teachers and decreased several support services and programs (Teacher Layoffs Proceed, District Projects \$83 Million Deficit, 
2012). Yet national trends suggested that as dropout rates increase, so do the rates of juvenile crime and drug use in neighborhoods. In other words, when students fail, so do neighborhoods, and vice versa; they are inextricably bound (Warren, 2005). Convinced by positive academic and social outcomes reported by such cities as New York, Chicago, and Cincinnati (Coalition for Community Schools, 2006; Children's Aid Society 2006; Dryfoos, 2000), combined with the promise of millions in School Improve Grant (SIG) money (CDE, 2010), San Francisco Unified School District (SFUSD) decided to explore the community schools approach. Beginning in 2009-10, SFUSD partnered with an initiative called New Day for Learning, an organization funded by the Mott Foundation, which was a longtime supporter of community schools initiatives, to pilot this strategy in five schools. Burton High School was the only high school chosen and the only school partnering with a Beacon.

The following year, San Francisco received School Improvement Grant (SIG) money, a three-year grant, which it used to help fund several schools in the Superintendent's Zones (SZ). The Zones served 10 of the highest need schools located in the city's traditionally most impoverished neighborhoods. The Mission and Bayview neighborhood's Community schools coordinators (CSC) were hired to help coordinate the community schools strategy at each school site, and this added a layer of leadership, which was a key feature of the district's strategic plan. Deepening its commitment to this approach, in 2012, SFUSD hired a Director of Community Schools, Dr. Hayin Kim, to spearhead the expansion and implementation of the community schools model. The school year finished with the Coalition for Community Schools' successful Community Schools Forum, for which I co-facilitated the community schools coordination 
preconference. The Forum helped put San Francisco's burgeoning community schools identity in the national spotlight. However, with SIG funds destined to sunset in 2013, SFUSD had to determine their next step. The tension was whether schools would be able to maintain the momentum they had created without the SIG money.

In 2013, all of the Superintendent Zone schools and a few schools that also had Beacon Centers became part of the District's Community Schools Incubator. In terms of funding, some schools still had SIG money; Beacons are primarily funded by the Department of Children, Youth and their Families (DCYF). Some schools paid for the coordinator and other services out of these budgets, and one school funded its community schools coordinator, itself, using neither DCYF nor SIG funds. These schools were given community schools coaches and met monthly as a cohort to discuss aspects of the model. I saw this incubator was a real opportunity for community schools professionals to practice the tenets of the community schools model around collaboration and equitable representation, and the variety of funding models around the table made for complex conversations. There were all school levels, and a range of needs, including increasing family engagement, securing adequate long-term funding, and supporting African American achievement. At the same time, coordinators shared similar challenges, such as getting buy-in from their principal and teachers and creating a working community schools team at their school sites. The fact that we were relatively disparate groups with varying agendas who were each involved in a collaborative process with differing levels of commitment sounded a lot like some of our school sites. Thus, the incubator meetings were good practice for what to do, and what not to do, when collaborating with a variety of stakeholders. One major benefit was that principals were required to attend some of 
the meetings, carving out some of each principal's much sought after time to just talk community schools model. Most of us had a difficult time getting an audience with our principals to talk about this strategy. One major barrier was that there was no co-created or stated goal that anchored the group, the importance of which will be discussed in the cross sector collaboration section.

One of the wins that bubbled up from that year was that Dr. Kim and her team customized the community schools model for San Francisco Unified School District. The 4-1-5, cleverly the area code for San Francisco, organized the tenets of the community schools model into four practices, one essential staffing function, and five key programs strategies that are viewed as essential for SF schools implementing the community schools model. The four practices include: (1) shared visioning, (2) matching needs and assets, (3) continuous learning and improvement, as well as (4) coherence and integration. The one additional essential function is the community schools coordinator, the person who plays a major role in managing the school's collaboration and alignment processes. The final component of this framework is comprised of five strategies that promote the scholastic and social success of students such as: (1) active family engagement (2) extended learning opportunities, (3) emotional and physical wellness, (4) strong academic and socio/emotional learning, as well as (5) college and career readiness. I find the 4-1-5 particularly useful in the configuration, wherein the community schools coordinator is an also an employee of the district. However, when the person who performs the one function of the community schools coordinator is a Beacon Director, all of the issues that come up around school-CBO partnerships also have to be worked through. While Beacons participate in these cohorts with the community schools run 
directly by the district, there are real differences in our jobs that make it challenging for us all to meet on common ground. Community schools coordinators who are directly employed by the district have the difficult and rewarding job of coordinating resources and helping their school site implement the model. As district employees, they have easy access to school data and generally do not supervise a staff or raise outside money. In general, community school coordinators (CSC) are brokering and managing relationships with parents, teachers, administration and other community partners. Coordinating details for implementing the model on multiple levels is a full time job.

Beacon directors like myself, who are charged with implementing this model, have those duties, plus managing a staff, oftentimes across multiple sites, raising money, and managing large budgets and contracts. Beacon Directors also have obligations to fulfill for our lead agencies (for example, the lead agency for my Beacon is the YMCA), as well as duties and meetings for funders and the Beacon Initiative. Additionally, because Beacon Centers are programs of community based organizations, and not the school district, they have limited access to data for the youth who are central to our programs. On the other hand, there are also advantages to being employed externally. For example, Beacons already have a unique position with San Francisco Unified School District in terms of a long-standing collaborative connection within schools, being both publicly and privately funded, as well as a long association with the community schools model. Therefore, schools with Beacon Centers have already established institutional relationships, to varying degrees, that will be beneficial as the community schools approach is being implemented. As such, Beacons have the potential to be a turnkey strategy for schools in San Francisco implementing the model, because chances are that 
these Beacons are already managing collaboration and relationships that prioritize school and community success. This description is not to set up an oppositional relationship with non-Beacon schools. Instead, it is a description of the positives and negatives that exist as a result of being a district employee versus a $\mathrm{CBO}$ partner employee, as well as the difference between having a Beacon versus not having one.

This discussion suggests some of the challenges that I've faced as a leader of community based organization working to integrate with a powerful entity like a school district. As a Beacon Director, I have built on the institutional capital that Beacons have garnered to implement this model at my school. However, I also realize that the wider population is not aware of the place or the impact of Beacons. What, then, are the Beacons and how have they related to the district and to the broader community schools movement?

\section{Community Schools Model and Beacons}

Many community schools scholars and practitioners credit Beacons as a prototype of the way schools, funders, and communities can work together to solidify a bright future for our children (Dryfoos, 2003; Keith; 1996; Quinn, 2011). Beacon Centers are charged with making schools into community hubs, which is one of the reasons the community schools professionals often refer it when discussing the origins of the community schools model. Currently, there are 8 Beacon hub sites in San Francisco, although 20 schools receive some portion of Beacon services or funding. San Francisco Beacon Initiative (SFBI) is the governing body that oversees all Beacons. The Department of Children, Youth and Families (DCYF) spends about 60 million dollars to fund programs and activities for youth and families in San Francisco's neighborhoods. 
throughout the city. Usually community based organizations, like the YMCA or Boys and Girls Clubs, are the lead agencies for a Beacon Center at a school site.

The San Francisco Beacon Initiative (SFBI) oversees all the Beacons Centers, using the Beacon bylaws. All major decisions are made by the Beacon Steering Committee, which includes stakeholders from schools, Beacons, CBOs, funders, students, and policy makers. Like the Beacon philosophy, the Steering Committee is an intentional blend of most of the stakeholders who might need or desire to have a voice in the decisions that impact Beacon operations. This type of a steering committee has been a model for other Beacon Steering Committees, nationwide.

Beacon Centers have another șlightly more complicated governing structure, but it is that structure that makes it a great candidate for implementing the community schools strategy from an institutional knowledge perspective. It is the practice of taking partners, with varying - sometimes even oppositional - agendas, and making them work for the benefit of the students and their families. This is where the Beacon director clearly has the function of the 1 in the 4-1-5 framework. Beacon directors have to manage three major agendas (at least): that of the San Francisco Beacon Initiative (SFBI), their lead agency, and of the school/SFUSD. Though Beacon directors are employees of the $\mathrm{CBO}$, neither the requirements of the school or the SFBI can be deprioritized. Thus, Beacon directors are skilled jugglers, as well as high-level collaborators, who have to hone the skills of balance in a dynamic environment that is simultaneously entrepreneurial and interdependent. In addition, Beacon directors must honor the rich Beacon history yet be willing to innovate in ways that push the model to the edge. That is where the community school strategy enters. 
Other specifics regarding Beacon structure is that the lead agency or $\mathrm{CBO}$ provides staff supervision, fiscal oversight, and HR services for the centers. The lead agencies for the Beacons are community based organizations, for example, the Bayview Beacon is a program of the Bayview YMCA. By having a $\mathrm{CBO}$ as a lead agency, the centers keep a strong foothold in the communities where the students from their schools reside. Structurally, that positions Beacon centers as both the insider and outsiders on school sites. Beacon Centers are outsiders as a non- school district program, but because many of our students' families also have connections with the $\mathrm{Y}$, we represent the families, which give the Beacon insider status. Most Beacons' hubs are located on school campuses and serve the youth and families of the school and neighborhood, so SFUSD is a very important partner and connection for Beacons, and vice versa.

On site, Beacon staff collaborates closely with students, parents, school staff, community members and other $\mathrm{CBO}$ programs to provide meaningful integral support services for students, families and communities. Beacons run a variety of afterschool programs, adult and parent engagement classes and activities, community events, employment programs, and case management and mental health support. For my center and for several other Beacon Centers, we also manage partnerships, such as with local colleges and businesses. This is one of the aspects that makes me often think that the 4$1-5$ community schools framework should really be $4-2-5$, at least in the case of Beacon directors, because.we actually are doing 2 jobs.

\section{Origins of the Beacon Model - "Pioneers of the School Based Afterschool World"}

The Beacon Initiative started in New York and came to San Francisco almost 20 years ago. In New York, Beacons were created to serve as a crime prevention strategy to 
curb the drug trade during the 1980s. A former San Francisco Beacon Initiative Director, Asha Mehta said to me in an interview:

The story goes that the commissioner of the Department of Community and Youth Development in New York, convinced the mayor that instead of building a prison barge, a floating prison barge to deal with the overflow of prisoner -- like a floating barge in the middle of the river -- that he should take that same $\$ 3$ million dollars and instead invest in Beacons. A pilot of school-based community centers that created positive opportunities for youth in their communities and some of the most low income, high crime neighborhoods in New York ... That impact of creating these positive prevention programs and opportunities would turn around the streets in New York then there would be less of a need for a place to house overflowing prisoners. So, that's how Beacons got started. AM, May, 2011

Over the next decade, crime in New York City decreased significantly, and it seems reasonable to attribute part of that shift to the investment the city was making in school-based programs that included afterschool activities, services for families, and having so many of the school buildings open for 12 hours per day. Richard Longo (2007) argues that Beacons were one of the prototypes for other school-community strategies such as the Harlem Children's Zone and the community schools work spearheaded by the Children's Aid Society.

Beacons then continued their innovative work in San Francisco beginning in the late 1990's. With funding from DCYF and SFUSD as the major partner, Beacons were able to keep school buildings open to the neighborhoods and surrounding communities. Specifically, they began to align programs and services with the school day needs, and run program any time after dismissal, especially at night and on weekends. Overall, Beacons were touted as groundbreaking and one of the very first programs that tried to connect student achievement with community health. In San Francisco, as was the case in New York, Beacons operated on the premise that programs for students alone would not consistently or sustainably increase young people's opportunities for success. Instead, 
Beacons seek to support all the pillars that undergird youth, including parents, neighborhoods, and schools, which sound very similar to the community schools model. Before I began studying the model, I thought having a Beacon and implementing the community schools model strategy was duplicative. However, as the school and my Beacon collaborated more closely and consistently, I came to understand that there are differences.

As Burton High School was one of the flagship schools chosen by New Day for Learning, the resources this organization and the spotlight of being a flagship school provided me with the support to build on my experience and knowledge base as a Beacon director. Thus, I used my profession background to collaborate and strengthen relationships with all stakeholders, especially with the Burton High School staff. I found out firsthand that although Beacons were a prototype for what is now called the community schools model, I could discern differences between the two concepts. While it is true that Beacons have a rich history of collaboration with various stakeholders and delivering quality programming, we have not always intentionally or methodically been on the same page with our school sites, in terms of goals. Much of the time, we have similar goals, especially around closing the achievement gap and increasing graduation rates, but determining the goals together in an intentional and collaborative process has not always been prioritized. Yet co-creating a vision and goals for the school community, including its partners, is an essential part of the community schools model. Intentional collaboration and tighter cohesion between the school and the Beacon have been keys to successfully implementing this strategy. In my experience, the school and Beacons no longer merely co-located on the campus, working toward goals separately but 
in tandem. Instead we are working with much more integration at almost every level, from the administrative teams to CBO staff meetings. We have developed shared goals, shared decision-making, and shared accountability. We also have demonstrated a new kind of equity that is reflected in our shared leadership.

As SFUSD embraces the community schools approach, examining collaboration, shared leadership and power dynamics will be crucial. In the first section, I explored the "What?" question, as in, "What is the community schools approach, in general, and what is its relationship with San Francisco Unified School District and with Beacons?" I also answered the questions, "What are Beacons, and what are the differences between Beacon philosophy and strategy, versus the community schools approach" and as well "What are the differences in the way that the 1 position (in 4-1-5 framework), functions?" The Bay Area is an excellent site at which to highlight these issues. SFUSD has been scaling up its community schools strategy, and other districts such as Oakland Unified School District and West Contra County are in various stages of adopting the community schools model. San Francisco has a long history of collaboration. Now it could potentially be the first to find a solution for what the best practices are to ensure the equitable integration of community based organization voice.

\section{Effective Cross Sector Collaboration}

In 2009 SFUSD began the effort to implement the community schools model. The effort was led by an initiative called New Day for Learning, which chose five sites to implement the approach. The principal of the high school where my Beacon is located and I quickly decided that we would create the best environment for our students and their families to achieve if we were to collaborate. Collaboration is a key theme in 
community schools literature (Epstein, 2004; Quinn, 2005; Sanders \& Lewis, 2006) as formerly distinct parties learn to work together toward a shared goal (Butterfoss \& Kegler, 2002). As is the case with any relationship, it needs the right kind of care and nurturing to thrive. I agree that collaborative relationships are imperative for implementing the community schools strategy, but I would argue that it is not the ultimate goal. I think many educators prematurely congratulate themselves for merely working together, yet the actual work to achieve the co-created goals begins only after entities understand how to partner.

Cross sector collaboration presumes three primary institutional sectors of society: public (government), private (business), and civil society also called the "third sector" (e.g., nonprofits or CBOs) (Grudinschi, Sintonen, Halikas, Kaljuen \& Puustinen, 2013; Selky \& Parker, 2005). Cross sector collaboration describes the process by which entities from different societal domains or "arenas" (Selsky \& Parker, 2005) unite to solve complex social issues (Bryson, Crosby \& Stone, 2006; Cairns \& Harris, 2011; Simo \& Bies, 2007). Examples can include universities and business, faith-based organizations and government, and my particular interest, K-12 districts and community-based organizations. Separately, these entities have their own agendas, imperatives, and goals. However, to impact deeper and broader social issues, cross sector collaboration is necessary (Dorado, Giles \& Welch, 2009; Grudinschi, et al., 2013; Kania, Kramer, 2011). This section will explore aspects of cross sector collaboration that are important for building highly functional and productive school-CBO relationships within the community schools framework. These components are: the Collective Impact framework, prework, and strong leadership from the top. 


\section{Collective Impact}

"They have embraced a new way of seeing, learning, and doing that marries emergent solutions with intentional outcomes." (Kania \& Kramer, 2013, p.95)

The literature of cross sector collaborations is particularly relevant within the

context of the community schools model because it details collaborating for a cause

(Bryson, Crosby \& Stone, 2006; Cairns \& Harris, 2011; Simo \& Bies, 2007). Ideally, these collaborations are attached to a measureable goal. It could be a short or long term goal, but there should be a stated outcome that guides the actions of this type of partnership. Strong cross sector collaborative relationships also feature prework, that is, time at the beginning of the process wherein buy-in and a sense of belonging is cultivated. Stakeholders are invited to the decision making tables. It can take the form of the stakeholders having a sense of integration and connected to mutually established goal, to each other, and to the success of each party individually and collectively (Business Higher Education Forum, 2009; Quinn, 2005; Simo \& Bies, 2007).

The third area that is important in these relationships is that they have avenues for input and feedback. They can be formal or informal, but these opportunities have to exist to ensure that all parties are assured that they are heard and that their contribution is valued. These parts of cross sector relationships help establish direction, trust and a sense of community, three factors that that indicate that the school-Beacon or $\mathrm{CBO}$ partnership has a solid foundation from which to launch into making mutually beneficial decisions (Bryson, Crosby \& Stone, 2006).

Because $\mathrm{CBOs}$ and schools collaborations represent cross sector partnerships, it will be useful to examine them using the lens of the Collective Impact framework (Kania \& Kramer, 2011). According to Kramer and Kania, in past most CBOs use the "isolated impact" strategy (p.4). That is, they implement solutions on a small scale, likely to impact 
one site or a narrow group. Because many of the issues that negatively affect students in urban schools are social problems, the parties crafting and operationalizing their solutions must represent more than one sector. Collective Impact was developed to give cross sector collaborative relationships a framework for tackling, and eventually solving, the complex social problems (p.5)

This framework includes five conditions that, when met, help align, strengthen, and focus cross sector partnerships, like schools and CBOs relationships, with the purpose of increasing the likelihood of partnerships successfully solving problems. These conditions are: common agenda, shared measurement system, mutually reinforcing activities, continuous communication, and backbone organization.

The first three conditions can be characterized as tools that help the separate entities blend into a working unit, focused on results. A common agenda is shared understanding of the issues and what steps will be taken to address them. From there, the school and community partners develop shared measurements, or indicators, and mutually beneficial activities that will determine their progress toward successfully solving the issues. These three conditions serve as tangible evidence that schools and CBOs are in a process of active collaboration.

The final two conditions, continuous communication and backbone organization are both the glue that consistently binds the collaborative union together. The backbone organization is the body that powers the collaborative process and provides the necessary support toward the goals established in the common agenda. In the strict sense of this condition, the backbone organization should be independent of the parties collaborating .However, for the purposes of this study, the backbone organization will be the 
community schools teams. School and CBO staff is more likely to stay the course, avoid problems and celebrate victories, if they are being kept current.

I have decided to focus solely on common agenda for my dissertation, as I think that this condition is foundational for successful cross sector collaboration. I maintain that if the shared agenda condition is met, the likelihood of cultivating successful collaborative relationship is high. As was previously mentioned, the shared agenda or mutually agreed upon goals should be solidified before partners start working toward a goal. This next section will explain the concept of prework.

Prework

All collaboration is a process, and the integrity and thoroughness of the process can dictate the quality of the outcome, be it increasing the involvement of girls in STEM or building a more cohesive community schools team (Grudinschi, et al., 2013; Huxham \& Vangen, 2003). Before implementing the process, there has to be a commitment, in this case from the school and non-district entities, to working together as well as agreements on how they will do so. This preparation ensures that the conditions for collaborations are favorable. In her study of three high schools that were collaborating with community-based partners, Sanders (2005) interviewed principals, team chairs, district staff, and community partners. One of her findings is that an important part of the partner formation process is preparation for collaboration. She found several factors that helped lay the groundwork for meaningful collaboration including: "broad support for partnerships, an engaged team responsible for partnership planning and implementation, adequate funding, and practical tools and guidance" (p.3). In other words, the entities, regardless of sector, should commit to the process before they actually begin working together. 
Additionally, Sanders's study, as well as others (Business Higher Education Forum, 2009; Quinn, 2005; Simo \& Bies, 2007) also found that productive cross sector collaboration requires an investment of time and commitment before it can be effective. In my experience, starting and helping others start to systematically embrace the community schools model, the prework or frontloading is often overlooked in the interest of saving time and from an eagerness to jump right into the process. But for best results, especially when two sectors intersect, such as a school (public) and a Beacon Center (nonprofit, $3^{\text {rd }}$ sector), there are at least four elements that must be considered before the real work of collaboration begins. These include: (1) cultivating buy-in and agreement from all parties on a shared goal, (2) managing expectations around the timeline for completion, (3) setting out what can realistically be accomplished during the timeframe, and (4) determining how many financial resources will be needed, as well as which entities will pay for what.

Researchers, Bryson, Crosby and Stone (2006) also support this notion of prework within the context of the model that they developed. In 2009, with assistance from New Day for Learning, my principal and I did take our time working through separate and conjoined processes to come to the conclusion that we wanted to become a community school. Central to this decision was giving ourselves permission to take as much time as was needed to commit to developing this collaborative relationship. Leadership Matters in Cross-Sector Collaboration

The role of leadership in cross sector collaboration can determine the intentionality and intensity of the partnership, as well as if and how the nonprofit program representation is included in decision making processes and bodies. Several 
studies pointed to strong leadership as one of the linchpins of successful cross sector partnerships (Business Higher Education Forum, 2009; Crosby \& Bryson, 2006; Dorado et al., 2008). Strong and positive leadership is particularly important when attempting to ensure that each party at the table has some agency and is recognized as a full partner. Most studies found that leadership and buy-in to the collaborative process from the top officials often seem to facilitate easier investment from others (Business Higher Education Forum, 2009).

In the case study of the Long Beach Seamless. Education Partnership, P-12, higher education, business and community organizations partnered to form the Long Beach Seamless Education Partnership (LBSEP). The Business-Higher Ed Forum (BHEF) chose 50 leaders from those groups to interview. The group's goal was to "develop a world class education system" (p.5) that none of them could alone. Eloy Oakley, President of Long Beach Community College, set the tone for the collaboration's work together by saying "Charles Steinhauser's [Long Beach Superintendent] success is my success," thus articulating the leaders' support for each other. Many of the interviewees quoted in this study commented that the attitude of the leaders set the positive and unified tone for the rest of the participants. Yet these leaders do not have to manage the commitment; often it is the community schools coordinator, with the help of the principal, who ensure that collaborative process advances.

In their study of MetroGIS, Crosby and Brysion (2010) explored government, nonprofit partner cross-sector collaborative efforts. MetroGIS is a geographic information system that promotes better public problem solving in the Minneapolis area. This group is comprised of $300+$ government and nonprofit organizations. The 
researchers developed a framework of propositions that focused on "initial conditions, processes and practices, structure, and governance, contingencies and constraints and outcomes and accountability" (p. 216). Crosby et al.'s model codified the LBSEP study's finding that leaders are able to set the tone better and more easily, either formally or informally, if they understand their audience and strive to get buy-in from their constituents (Crosby \& Bryson, 2010). This buy-in is important because it facilitates the idea that all partners have a voice. Like Ghamrawi's 2011 study, Crosby and Bryson (2010) described trust in the leaders as imperative to successful cross sector collaboration. When attempting to ensure that groups with disparate mandates and agendas have an equitable representation at decision-making tables, leaders have to have established trust, particularly to negotiate the power relationships that surface.

Within the community schools model framework, these leaders could be superintendents at the district level, principals and community schools coordinators at the school site, and directors of nonprofits. Many leaders champion cross sector partnerships because they promote cooperation, cohesion, and acceptance of the cross sector collaboration concepts from the top down. These leaders are essential for setting a positive tone and promoting accountability and sustainability. Principals and superintendents have this role within schools. In a best-case scenario, both of those positions are on record supporting the implementation of the community schools approach. It is a part of a strategic plan, as was the case for San Francisco Unified School District, Oakland Unified School District, and Contra Costa County Unified School District. As instructional leaders, at least principals should be fully invested 
conceptually in this collaborative process, in order for the rest of the stakeholders to take it seriously.

The literature corroborates the notion that having a strong coordinator is important in cross sector collaboration. This person organizes and facilitates the logistical components of cross sector partnerships. Dorado, Giles \& Welch's study looked at 11 service learning (SL) partnerships in New England, which consisted of teachers, a community partner, and institutions of higher education (IHEs). In this study, the university partner was charged with the coordinator role, ensuring the formation and operationalization of the actual collaborative body. Often the person who has this role in community schools in SFUSD is an actual community schools coordinator employed by the district or by a CBO (Warren, 2005). In a community schools model framework, cross sector partners co-create a vision that might lead to shared leadership, shared accountability, and shared language that could eventually lead to shared success

Schools and community based organizations usually implement the community schools approach once they have determined that working together to solve problems would be more efficacious than would isolated efforts. However, though these cross sector collaborations seem to make logical sense, the experience of developing a new kind of relationship can still be difficult, as the next section will discuss.

\section{Barriers to Successful Collaboration}

Because neither schools nor community based organizations can solve the issues that face schools and students on their own, tighter collaboration under the community schools model affords the groups a framework to be connected to their goals, and each other's success, in ways that they perhaps had not been possible before. However, several barriers to successful collaboration can surface. For example, though schools and 
CBOs often have similar ultimate goals such as increasing graduation rates, at times their agendas may diverge around such details as priorities, timing, urgency, and methods. Conflicting agendas can breed mistrust in a partnership and choke off the motivation to work on issues as a team.

Another barrier to schools and CBOs working together is the lack of time. With each entity having its own priorities and mandates to satisfy, it can be difficult to meet to develop the actual functional partnership. Effective partnership development, grounded in the community schools strategy, would involve co-creating a shared vision, measureable goals, and mutually agreed upon evaluation processes. Failure to make time to do this preliminary work can result in the partners functioning in silos.

Finally, schools' primary focus is academic. CBOs can focus on academics, as well as other areas of students' lives including, leadership, sports, mental health, socioemotional development, and providing a safe space afterschool. Sometimes, teachers remark that students who are failing should not be able to participate in extracurricular activities. Most $\mathrm{CBO}$ agree that academics are important, but that it is equally important to provide students with other avenues to be successful, outside of academics. The "pure" academic vs. whole child approach can pit teachers and CBO workers against each other. This type of opposition between partners can be lethal to successful collaboration.

Though the benefits of multi-sector partnering are many, it is still a complex and often challenging process. I can attest personally to the fact that it is often difficult for a school and a CBO partner to co-create a vision, as well as maintain focus on goals. It can seem to be almost impossible to change the traditional norms of the school or district and 
nonprofit partner relationship, yet implementing this strategy requires such a shift. These issues can impede collaboration, in general, and do not facilitate equitable representation of CBO voice, in particular (Grudinschi et al, 2013; Huxam \& Vangen, 2000; Selsky \& Parker, 2005; Vangen, 2003). Trust can be a facilitator of collaboration, as was referenced in the Crosby model. Inversely, a lack of trust is an enormous obstacle to the collaborative process. Kegler, Hall, and Kiser (2010) interviewed 61 people who were on 34 faith-based health teams. They found similar factors that facilitated successful coalition building within this group, but the barriers were notable. Because this coalition consisted of faith-based organizations, other community members, healthcare professionals, and policy makers, the obstacles to building a successful coalition included people's general distrust of faith based organizations and government agencies (both separately and together), unease with the diversity of faith based organizations, a perception of hidden agendas, and frustration with lack of a common language. Clearly, these difficulties can be recognized in collaborative work in educational settings as well, as was evidenced by Ghamrawi (2011), who found trust is integral to collaboration between teachers and principals.

Building and maintaining trust, in the business and nonprofit arenas can be an issue as well. Selsky \& Parker's (2005) work posits that trust in the "by-product of prior trustful social interactions" (p.856). In other words, acting with integrity builds the social capital needed to support strong relationships. Businesses deal with contractual agreements, whereas nonprofits build trust using their mission, shared values, and vision. Issues arise when there is misalignment within these contexts. 
As an example, a school and a CBO agree to adopt the community schools strategy, but then the school continues to set goals without input from the CBO partner, just as they did before the community schools model. In my experience, this leaves the CBO partner suspicious of the school's motives, which decreases trust. Conversely, Bryson, Crosby and Stone found that "collaboration partners build trust by sharing information and knowledge and demonstrating competency, good intentions, and follow through" $(2006$, p.48). For instance, the school and partner agree to do a joint conference directed at families. The school and partner work together both virtually and in person. Parties come to meetings with their tasks completed, and eventually, the summit goes off without a hitch. Each intergroup action builds trust.

Within the context of the community schools model, as all stakeholders work together, believing in the integrity of the school staff or CBO partner will be imperative. From experience, I know that some CBO programs have not been $100 \%$ reliable to the school, while schools have not always been as welcoming or helpful to the nonprofit partners. This strategy is an opportunity to reset and to begin to perform actions that build the trust needed to grow and maintain a healthy, long lasting, and collaborative relationship.

In my case, the trust and respect that the principal and I have in each other as leaders of different sectors has allowed us to work through mistakes and mishaps to accomplish results. For example, because of my position as a Beacon director, the principal allowed me to facilitate several professional development meetings for the teachers during my first year. While making what I thought was a joke, I said something that offended several people. Instead of prohibiting me from doing any more workshops, 
he fielded the complaints and affirmed his confidence in me and my ability to help the school. I have led countless professional develop meetings since then.

\section{Equitable Integration of CBO Voice}

A significant challenge to cross sector collaborations is ensuring that the community voice is equitably represented and integrated. This common challenge is particularly important in the community schools model, because it affects the degree to which CBO partners take meaningful roles within schools' leadership and decision making structures (Anderson-Butcher, Lawson, \& Iachini, 2010; Bosma, Sieving, \& Ericson, 2010; Gajda, 2004). In the traditional school/CBO relationship, a lack of $\mathrm{CBO}$ input would not have been unusual or problematic. As the public schools are bound by government regulations and policies around educating students, school priorities often trumped those of their nonprofit partner, frequently rendering nonprofit partner input less compelling. For example, school priorities were established by the district or within school staff teams during meetings that happen during the school day; therefore, the $\mathrm{CBO}$ voice could easily be disregarded. However, as schools adopt the community schools strategy, under which schools and partners make a deeper commitment to work together toward solving complex problems, nonprofit partners should be equitably integrated into school leadership bodies that make decisions, particularly regarding the resources that they bring to the table. Under the community schools model, schools and CBOs co-create a vision that will accommodate school mandates as well as $\mathrm{CBO}$ obligations (Gold, Henig, \& Simon, 2011; Hill, 2011). How do they share leadership and how does the process of decision making change? The hope is that this study illuminates some of those areas.

The phrase, "equitable integration," can be confusing in education circles. In a public school setting, the term integration often refers to special education. Integration pertains 
settings where students with and without special needs are taught together in the classroom for part of the school day. Studies have shown that special education students in this environment do not feel connected to their peers. In contrast the term inclusion refers to special and general education students learning in the same classrooms full time. The full inclusion of special needs students builds community and a sense of belonging. This strategy is currently being piloted in SFUSD (Konza 2008). However, for the purposes of this paper, integration implies that the $\mathrm{CBO}$ representation is woven into the fabric of the decision making body. Its input valued by the group and there is a feeling of community and belonging.

As has been discussed, equity in education has to do with all students having the resources that they need to be successful. This concept is also present in the discourse around cross sector educational partnerships (Casey, 2007; Patterson, 1998). For this paper, equitable means as much as is appropriate, fair or needed relating to decision making power. Generally, Beacon directors and $\mathrm{CBO}$ partners would probably be able to contribute less meaningfully to a discussion about restructuring the math department's administrative duties, than they would decisions regarding support services and afterschool activities. However, the intention would be that when appropriate, as intentionally determined by the principal with the Beacon or $\mathrm{CBO}$ representative, the $\mathrm{CBO}$ voice is heard and valued. Thus, equitable integration of $\mathrm{CBO}$ representation and voice in school leadership structures does not imply equality or sameness in terms of shared decision making. More so, it recognizes, but does not devalue the differences between the partners who come from different sectors, and draws upon the strengths of each (Casey, 2007). 
At the heart of the issue seems to be the unequal and often unacknowledged power dynamics that are inherent in this type of partnership. In previous iterations of the school CBO collaborations, this imbalance in power was accepted and expected. In my experience, schools did not notice the inequality and as a CBO partner, I learned to work within the parameters that had been established. The next section delves deeper into this issue of power dynamics, as it is central to how schools and CBOs work together, to the inclusion of $\mathrm{CBO}$ voice, and eventually, to both groups sharing leadership and decision making duties equitably.

\section{Power Dynamics in Cross Sector Collaboration}

As the examples drawn from the literature discussed above show, cross sector collaborators are generally not equal partners. One collaborator often has more decisionmaking power as related to the goal, mandates, and resources. In the case of public schools contrasted with $\mathrm{CBO}$ partners, public schools are funded by and accountable to the government; they are part of the government sector. CBO partners are part of the third or nonprofit sector; when they are located on a school campus, as is the case with Beacons, they generally conduct programs and services at the behest of the school, although are accountable to their funders, who can be public or private. In practice, government mandates often trump funding requirements of nonprofit partners, because schools must demonstrate compliance to public policies or legislation, such as No Child Left Behind. Additionally, the principal is in charge of what happens at the school site, including the building, grounds and what programs are allowed to serve students there. Nonprofit partners, like my Beacon or the Beacon Initiative, have to ask permission to be on campus, write Memos of Understanding and contracts with the school or district, and 
follow school rules in order to stay in good standing with the school community.

Because I have to make sure that I stay in good standing with the school, the school generally has the most power in the school-CBO partner dynamic.

In order to support students and families better, schools that are implementing the community schools model invite their partners to collaborate, not so much as temporary guests, but as integral parts of the community. Indeed, partners bring needed financial resources and human capital to schools, and so it seems logical that the balance of power would shift to accommodate this new configuration and tighter relationship. Ideally, there would be less exercising power over, and more sharing power with. Power dynamics bring up the concept of fairness and its role in the success of these collaborations. It brings up the concept of what is needed in a healthy and permanent relationship, like a marriage. But an unacknowledged imbalance in power dynamics between partners can make collaborating problematic. This section will look at some of the literature that addresses the role of power dynamics in cross sector collaborations. Again, I've pulled examples of cross sector collaborations from different industries. However the issues that arise are entirely transferrable to the school/CBO paradigm.

When the literature talks about power in cross sector collaboration, for the most part, it is in the context of imbalanced power dynamics and how that negatively impacts the successful sharing of leadership and collaboration (Allen, Culhane-Pera, Peragment, \& Call, 2011; Githens, 2009), particularly during conflict or times of mistrust (Bies \& Simo, 2007). Bryson, Crosby and Stone found that though conflict and disagreements are normal in collaborations, "collaborations are more likely to succeed when partners work to moderate power dynamics" (p.48). In the Bies and Simo mixed method study 
discussed in an earlier section, many issues, particularly based on mistrust, surfaced as a result of new and already established agencies vying for limited resources and determining which organization could authentically speak for the people displaced by hurricanes. In this case, imbalanced power dynamics arose between the newer organizations and the older ones. People and the government agencies had to choose which agencies to support. This internal and external competition bred overall mistrust in the process of collaboration and became a hindrance to helping people rebuild after the disaster. This struggle is analogous to the power dynamics that can occur amongst the players of the decision making bodies at schools, including teachers, parents, and nonprofit entities.

As I have mentioned, in public school/nonprofit relationships, schools generally have the greatest decision-making power, and correspondingly, assume the greatest liability for programs on campus. An issue that arises on the $\mathrm{CBO}$ side is that it was invited in by school officials, and correspondingly, could be invited to leave by these same officials. The feeling that one party holds significantly more power in school/nonprofit relationships can trigger insecurity and mistrust that is detrimental to any cross sector collaborative relationship. Githens (2009), found similar results when conducting an action research account of his position of authority and how he used power, while creating a collaborative professional community. He found that the "explicit mindfulness to combining collaborative leadership approach and examining power dynamics... continuously presented itself as an issue" (p.427). Additionally, he found that might be useful to have a more direct discussion of power dynamics. This 
might help to facilitate authentic power sharing versus "the illusion of egalitarianism" (p.427).

Githens's point is well taken. In my experience, the issue is not so much the imbalance of power. Rather, it is the reluctance to acknowledge this imbalance that is problematic. I have seen this silence exacerbate negativity and breed mistrust, which weakens collaborative relationships. I know that this issue is more salient on the nonprofit partner side. In my experience, when partnering is productive, there is no motivation bring up complicated issues. However, in my experience that is precisely the time to check in with school staff around issues like the power dynamic. When we began to implement the community schools model, my principal and I had a moment wherein I was able to acknowledge that I felt that our place at as a Beacon at Burton was tenuous. That admission of vulnerability opened up the conversation that resulted in the principal being more conscious of making sure I was at the decision-making tables. Our conversation and subsequent actions solidified the trust we had been accruing in our relationship. There is still an imbalance, but there is also acknowledgement and more equitable integration of not just my program, but of other $\mathrm{CBO}$ partners as well.

Thus far, this paper has examined collaboration before the community schools model, the community schools model, itself, as well as their barriers to success. Subsequently, there was an exploration of the specifics of cross sector collaboration, and one of its major barriers, imbalanced power dynamics. The next section discusses the practice of sharing leadership, which, as I have said before, is mentioned in the community schools literature but hardly ever fleshed out. However, without explicit focus on sharing leadership to ensure that $\mathrm{CBO}$ representation has decision making 
power, CBO partners might still be seen, yet unheard, when major decisions are made.

An additional focus on shared leadership, as a part of the collective impact framework, would not only have a seat at school decision making tables, but most importantly, they would have a voice.

\section{Shared Leadership}

The last component that will set up a school-CBO partnership for success in a community school is the sharing of leadership duties. It is one of the most important aspects, and simultaneously, is one of the least fleshed out in the literature. Shared, also known as distributed or partnered leadership, allows a school and community partners to flatten the leadership structures such that one person (such as the principal) does not dominate the decision-making process. This is a major departure from how schools and outside organizations have operated together in the past (Lambert, 2002; Yaron, 2009). Usually, the principal or school district representative made all major decisions with little or no regard for the input or obligations of its community partners. However, for the community schools approach to function properly, stakeholders' contributions and requirements are considered, and each group has a measure of power in decision-making processes.

Internal conflict arises many times because the entities at the table have different, sometimes competing, obligations to fulfill for their own funders or constituencies (Hill, 2011). As was discussed in the power dynamics section, this tension can breed discord that might result in distrust, isolation, and gridlock -- the enemies to accomplishing goals as a cohesive group to help students. Shared leadership is an integral part of the community schools strategy because it fosters cohesion, buy-in, trust, and equitable cross sector collaborative relationships, wherein there is an agreed upon goal. 
Shared leadership has not been studied extensively as a component of the literature of the community schools model, although, it is mentioned (Blank, Melaville \& Shah, 2003; Federation of Community Schools, 2008; San Francisco Public Schools, 2010). Nonetheless, shared leadership plays a pivotal role as practice that allows school and communities members to be heard at decision-making tables. In general, distributed or shared leadership seems to be growing in popularity as a tool for promoting staff satisfaction and student achievement in the field of education. These models are also called team participatory or distributive leadership (MacNeil \& McClanahan, 2005; Harris, 2004). Studies show that teams that practicing shared leadership experience more motivation and buy-in over the long term than those that practicing top-down leadership (Solansky, 2008). As I have discussed, buy-in is an integral component of the collaborative community schools model relationship.

The accepted management dynamic in most schools consists of the principal as the educational leader and main decision maker, while teachers and other staff take direction. Several studies have examined the process of developing a shared leadership model that includes teachers and principals (Lambert, 2002; Moxley, 2000). In her frequently cited study, Lambert (2002) surveyed educators and interviewed a smaller group of principals and teachers across 15 schools in the US and Canada about their perceptions around sharing leadership. Her research specified that key factors in a strong distributive leadership dynamic include clear communication, constant reflection, shared visioning, and the use of inquiry-based information to guide practice. Further, other researchers (Kocolowski, 2010; Moxley 2000; Yaron, 2009) agree that mutual respect, balance of power, and shared responsibility are imperative for groups to build the social 
capital necessary to partner as leaders. These findings are particularly useful as nondistrict entities are incorporated into a shared decision making process as a way to break down barriers, and build the trust needed to focus on the success of the kids. Clearly trust is a key element in collaboration, especially, as noted by Guamrawi (2011), where there is an imbalance of power. The findings of her study of teachers and principals in Beirut supported the idea that establishing trust contributes to an environment where teachers and principals were more confident and freer to collaborate. This confidence and freedom meant that leadership functions were spread among them.

I have seen a fair amount of variation in what is considered sharing leadership. At Burton, an example of the form that shared leadership has taken has been integrating a Beacon staff person on all appropriate leadership bodies of the school, including the top administrative team that consists of the principal, vice principals, and myself. At other schools in the district, configurations have been more hierarchical, although, the principal and vice principals sit in on the leadership bodies, such as the administrative teams or school site council, and there is a system for reciprocal communication. I have heard community schools leaders, Jane Quinn and Marty Blank, say on countless occasions, "If you've seen one community school, you've seen one community school." That saying also applies to the shared leadership relationship. The most important aspect of shared leadership in the community schools model is that there is a mechanism by which the $\mathrm{CBO}$ programs have input. Further real shared leadership also means that the principal feels like this $\mathrm{CBO}$ input provides additional capacity on the school wide team to make well-considered decisions or plans. 


\section{Conclusion}

San Francisco has an amazing history of collaboration where young people and their families are concerned. The 20 year public/private partnership between SFUSD and the San Francisco Beacon Initiative is an important example of this work, and is a natural fit for the community schools effort that has begun to take root. Having frameworks and strategies, such as Collective Impact and the community schools model, is smart as way to ensure organization and structure, especially when disparate agendas are in play. However, without strong and healthy relationships between stakeholders who are committed to a goal, but also to each other, the most important element is missing -- like a car without an engine. It is the dedicated relationships between schools and Beacons or lead agency partners (and sometimes both), grounded in trust and mutual respect that powers partnerships passed short term setbacks, to long term success.

It is important to remember that the playing field is not level, strong collaborative relationship notwithstanding. Schools, as the government entity, will always have the ultimate authority on a school site. If that is the case, as San Francisco schools implement the community schools model, how do building a common agenda, sharing leadership, power dynamics, and the equitable integration of $\mathrm{CBO}$ voice look at site level? Does the imbalanced dynamic impact the way a school and a Beacon, or other lead agency partner, share leadership? How is sharing leadership different for schools with Beacons, without Beacons or who have both a Beacon and a lead agency partner. These questions and more will be examined in the next paper, which is a qualitative cross case analysis of three schools in San Francisco that are implementing the community schools approach. 


\section{References}

Allen, M. L., Culhane-Pera, K. A., Pergament, S., \& Call, K. T. (January 01, 2011). A capacity building program to promote CBPR partnerships between academic researchers and community members. Clinical and Translational Science, 4, 6, 428-33.

Anderson-Butcher, D., Lawson, H. A., Iachini, A., (July 01, 2010). Emergent evidence in support of a community collaboration model for school improvement. Children \& Schools, 32, 3, 160-171

Blank, M. J., Melaville, A., \& Shah, B. P. (2003). Making the difference: Research and practice in community schools. Washington, DC: Coalition for Community Schools..

Bosma, L. M., Sieving, R. E., Ericson, A., Russ, P., Cavender, L., \& Bonine, M. (2010). Elements for successful collaboration between K-8 school, community agency, and university partners: the lead peace partnership. The Journal of School Health, 80(10), 501-7.

Bryson, J., Crosby, B., \& Stone, M. (2006). The design and implementation of crosssector collaborations: propositions from the literature. Public Administration Review, 66(s1), 44-55. http://dx.doi.org/10.1111/j.1540-6210.2006.00665.x

Business Higher Education Forum. (2009). Improving Education Through Collaboration (pp. 1-17).

Butterfoss, F. \& Kegler, M. (2002). Toward a comprehensive understanding of community coalitions: Moving from practice to theory. In R. DiClemente, R. Crosby, \& M. Kegler (Eds.), Emerging theories in health promotion practice and 
research in health promotion practice and research. (pp. 157-193). San Francisco, CA: Jossey-Bass.

Cairns, B., \& Harris, M. (March 15, 2011). Local cross-sector partnerships. Nonprofit Management and Leadership, 21(3), 311-324.

Casey, M. (2007). Partnership - Success factors of interorganizational relationships. Journal of Nursing Management, 16(1), 72-83.

Children's Aid Society (2006). Summary of the Children's Aid Society community schools results to date. New York, NY: Children's Aid Society.

Conger, J. A., \& Pearce, C. L. (2003). A landscape of opportunities: Future research in shared leadership. In C. L. Pearce \& J. A. Conger (Eds.), Shared Leadership (pp. 285-303). Thousand Oaks, CA: Sage.

Crosby, B. C., \& Bryson, J. M. (2010). Integrative leadership and the creation and maintenance of cross-sector collaborations. The Leadership Quarterly, 21(2), 211-230.

Dorado, S., Giles, D., \& Welch, T. (January 01, 2009). Delegation of coordination and outcomes in cross-sector partnerships. Nonprofit and Voluntary Sector Quarterly, 38(3), 368-391.

Dryfoos, J. (2000). Evaluation of Community Schools: An Early Look, Washington, DC: Coalition for Community Schools.

Dryfoos, J., \& Maguire, S. (2002). Inside full-service community schools. Thousand Oaks, CA: Corwin Press.

Dryfoos, J. G. (2004). A community school in action. Reclaiming Children and Youth, 11(4), 203-5. 
Epstein, J. L. (2005). A case study of the partnership schools comprehensives school reform (CSR) model. Elementary School Journal, 106(2), 151.

Epstein, J. L. (2008). Improving family and community involvement in secondary schools - New approaches make partnership programs possible. The Education Digest, 73(6), 9.

Gackle, J (April, 2013) http://www.sfexaminer.com/sanfrancisco/black-pacific-islanderstudents-in-san-francisco-improve-graduation-rates $/$ Content?oid $=2336433$

Gajda, R. (January 01, 2004). Utilizing collaboration theory to evaluate strategic alliances. American Journal of Evaluation, 25(1), 65-77.

Ghamrawi, N. (2011) Trust me: Your school can be better-a message from teachers to principals. Educational Management Administration Leadership. 39, 333-348.

Githens, R. P. (2009). Leadership and power in fostering a collaborative community in a non-profit professional organization. Systemic Practice and Action Research, 22(5), 413-429.

Grudinschi, D., Sintonen, S., Hallikas, J., Kaljunen, L., \& Puustinen, A. (January 01, 2013). Management challenges in cross-sector collaboration. Innovation Journal, $18(2), 4-22$.

Guerrero, G. (2011, February). Community schools and school improvement grants supporting student and school success in San Francisco. Retrieved from San Francisco Unified School District website: http://www.sfusd.edu/en/assets/sfusdstaff/about-

SFUSD/files/initiatives\%20and\%20plans/files/SFUSD_Comm_Sch_SIG_Webina r_2\%2028\%2011.pdf 
Harris, A. (2005). Reflections on distributed leadership. Management in Education, $19(2), 10-12$.

Henig, J. R., Simon, E., \& Gold, E. (December 01, 2011). Calling the shots in public education: Parents, politicians, and educators clash. Dissent, 58, 34-39.

Hill, C. R. (December 07, 2011). Power sharing: building community school relationships from friendship to marriage. Afterschool Matters, 14(14), 48-51

Huxam, C \& Vangen, S. (2000). Ambiguity, complexity and dynamics in collaboration, Human Resources 53(6), 771-806.

Jackson, S. (2000). A qualitative evaluation of shared leadership barriers, drivers and recommendations. Journal of Management in Medicine, 14(3/4), 166-178

Kania, J. \& Kramer, M. (2011). Collective impact. Stanford Social Innovation Review, $26-40$

Kegler, M. C., Hall, S. M., \& Kiser, M. (2010). Facilitators, challenges, and collaborative activities in faith and health partnerships to address health disparities. Health Education \& Behavior, 37(5), 665-679.

Keith, N. Z. (February 01, 1996). Can urban school reform and community development be joined? The potential of community schools. Education and Urban Society, 28(2), 237-68.

Kocolowski, M. (2010). Shared leadership: Is it time for a change? Emerging Leadership Journeys, 3(1), 22-32.

Lambert, L. (2002). A framework for shared leadership. Educational Leadership, 59(8), 37-40. 
Lambert, L. (2006). Lasting leadership: Study of high leadership capacity schools. The Educational Forum, 70(3), 238-254.

MacNeil, A, McClanahan, A (2005). Shared leadership. Connexions, Version 1.2

Moxley, R. S. (2000). Leadership and spirit. San Francisco, CA: Jossey-Bass.

Quinn, J. (December 07, 2005). The children's aid society community schools: A fullservice partnership model. New Directions for Youth Development, 2005, 107, 15 26.

Quinn, J. (2009). Community schools: A strategy, not a program. Visiting Scholars Series, Spring, 2009, vol. 2

San Francisco Unified School District (2012, May 8). Teacher layoffs precede, district projects \$83 million deficit. Retrieved from San Francisco Unified School District website: http://www.sfusd.edu/en/news/current-news/2012-newsarchive/05/teacher-layoffs-proceed,-district-projects-\$83-million-deficit.html

Sanders, M. (February 01, 2004). Community involvement in schools: from concept to practice. Sage Urban Studies Abstracts, 32(1)..

Selsky, J. W. \& Parker, B.. (2005). Cross-sector partnerships to address social issues: challenges to theory and practice. Journal of Management, 31(6), 849-873.

Simo, G., \& Bies, A. L. (2007). The role of nonprofits in disaster response: An expanded model of cross-sector collaboration. Public Administration Review, 67(1), 125142 .

SFUSD School Data Everett http://www.sfusd.edu/assets/sfusdstaff/rpa/sarcs2/hilights/sahl-529.pdf 
SFUSD School Data Hillcrest http://schoolratings.com/school_details/38684786041156.html

Solansky, S. (2008). Leadership style and team processes in self-managed Teams. Journal of Leadership \& Organizational Studies, 14(4), 332-341.

Vangen, S. (2003). Nurturing collaborative relations: building trust in interorganizational collaboration. The Journal Of Applied Behavioral Science, 39(1), 5-31. http://dx.doi.org/10.1177/0021886303039001001

Warren, M. R. (2005). Communities and schools: a new view of urban education reform. Harvard Educational Review, 75(2), 133-173.

Yaron, J. (2009). Shared leadership - practice and perceptions of teachers in a virtual community. Unpublished dissertation Hebrew University. 


\section{Paper 2 \\ Putting the Community in Community Schools: A Comparative Case Study}

\section{Introduction}

The community schools movement has garnered traction lately. Superintendents in cities from Hartford to Oakland have declared their districts community schools districts with the directive that all schools will eventually implement this approach. To take a specific example, New York just passed legislation investing \$150 million dollars to turn the state's lowest performing schools around using community schools strategies (Harris, Nov. 3, 2014). Among educators, scholars, and advocates, a consensus is rising that schools can't do it alone. A community schools strategy supports forming collaborative relationships between schools and stakeholders, particularly with community based organizations (CBOs), to share resources that increase opportunities for success for young people and their families. However, the cross sector collaboration that is foundational to this model can be extremely challenging.

In my 20 years of experience in education, the traditional way that schools and their partners interact can be characterized as creator (school) and implementer (partner). This means that the school or district staff set the priorities for the school, while the partners design and implement programs to help accomplish these goals. Or not. Sometimes the needs of the school and CBO program on campus have no connection or relation, except as co-locators in a building. When a school implements a community schools approach, this dynamic must shift such that school staff and partners evolve into co-creators of the goals, and often, co-leaders of school. The assumption is that if school and $\mathrm{CBO}$ staff combine to develop partnerships in which they feel mutually trusted,

valued, included, and respected, this effort will result in a stronger relationships that will 
be the foundation for solving difficult educational problems (Bryson, Crosby, \& Stone, 2006; Kania \& Kramer, 2011; Simo \& Bies, 2007).

Strong relationships are the cornerstone of successful school and community partnering, as well as an important tool in stakeholders' work to eliminate the entrenched and persistent issues that plague our schools and neighborhoods (Bryk, 2010; Dryfoos, 2007; Epstein, 2008). Yet some practices support strong mixed sector collaborative relationships, while others undermine them. As schools and community based organization partners embrace the community schools approach, their relationships should grow deeper, more integrated, and interdependent, instead of remaining mired in the traditional separate or tangential manner of relating.

To examine how a progressive urban district is embracing the community schools approach, this paper makes a comparative case study of three schools that are implementing the model as part of the plan by San Francisco Unified School District (SFUSD). The three school sites have different community school configurations, which is appropriate for SFUSD, as the district uses a range of collaborative models. Two of the three schools collaborate with Beacon Centers on site, although in different capacities. As Beacons have been touted as the model for full service community schools (Dryfoos, 2002), they deserve some special focus.

The purpose of this paper is to examine how the schools and nonprofit programs collaborate to build strong, meaningful relationships that address entrenched educational problems. It also seeks to understand what practices, if any, these school sites employ to facilitate the equitable inclusion of community based organization partners at appropriate decision making tables, specifically in terms of shared leadership practices. While strong 
meaningful relationships support successful outcomes, entrenched educational problems are equitable integration. Finally, this study investigates the role of power dynamics and their impact on the school-CBO relationship when the entities attempt to practice shared leadership. These school collaborations will be viewed through the lens of the Collective Impact framework (Kania \& Kramer, 2010). My research question for this paper is:

- How do SFUSD community schools, including those operating with and without Beacon Centers, equitably integrate their community based organizations (CBOs) into the leadership structure of their community schools team?

Across the three sites, I studied the major roles within their community schools team, namely that of the principal, community schools coordinator or Beacon director, and lead agency partner. I examined how these partnerships did or did not make use of shared leadership and how they handled power dynamics. A study of these factors lends insight into how the community schools staff facilitates collaboration and integration with $\mathrm{CBO}$ partners to share decision making responsibilities.

\section{Collective Impact - Conceptual Framework}

Collective Impact is a useful conceptual lens through which cross sector collaborations can be examined, such as the ones involved in implementing the community schools approach. John Kania and Mark Kramer (2011) created the framework to help partnerships move from isolated impact, meaning collaborative relationships that result in small scale change, to building fortified and interconnected relationships focused on solving a persistent social or educational issue. John Kania, writing along with Fay Hanleybrown and Jennifer Juster (2014) developed the framework further, saying that to have strong and collective impact, collaborators must have an 
understanding of three areas: "who is engaged, how they work together, and how progress happens" (p.2). The authors name five conditions that help partners answer those questions. Paraphrased, they are:

1. Common agenda or shared visioning - mutual understanding of the problem and a common approach to solving it. It answers the question: "What do we want to see changed?"

2. Shared measurement - common idea for evaluating success.

3. Mutually reinforcing activities - a plan of action that relies on coordination and cohesion.

4. Continuous communications - Developing relationships and trust through prework; build trust and interdependence

5. Backbone support organizations - organization separate from the partner that can coordinate to process. In the case of community schools, the backbone function would be filled by the Community Schools Team focused on supporting effective partnerships at a school

According to Kania and Kramer (2011), creating a common agenda is one of the most important steps in forming successful collaborative relationships. Given the fact that the partners, such as schools and community based organizations, often have different goals or priorities, it infuses the partnership with a single purpose that they create together or at least agree to. Though all of the conditions are important, for this study, I focus on the common agenda condition because it unites partners under a shared purpose. Thus, co-creating a shared agenda helps the schools and outside partners increase the cohesion in their collaborative relationship so that they are better able to 
function as a unit. However, in my experience, establishing a common or shared agenda does not mean that community voice will be integrated equitably.

To answer the question of equitable integration of $\mathrm{CBO}$ voice, the next sections will outline what I mean by equitable integration, shared leadership practices, and power dynamics. I hypothesize that forming partnerships, using shared goals and agendas, is a first step. Shared leadership practices function as the equalizing mechanism for schools and CBOs, to actualize the shared agenda in a way that is fair to all parties. A complication, however, is that in co-creating a common agenda does not ensure equitable inclusion in decision making and leadership among the entities. Therefore, to begin analysis of school site partner relationships, I turn to define the equitable integration of CBO voice. The subsequent sections will examine the nature of the shared leadership practices within the community school teams, and how power dynamics impact the equity of these relationships.

\section{Equitable Integration of CBO Voice}

According to the community school literature, as schools implement these strategies with nonprofit partners, their relationships shift from independent co-locators to collaborative partners, wherein the entities are more closely aligned and connected (Blank, Melville, \& Shah, 2006). With that shift, CBO partners should have more opportunity to provide input to the school's decision making processes (Henderson, 2011; Sanders, 2005). Equitable integration refers to CBOs having input in decisions that make sense to their own mission or expertise, especially when they are tied to reaching mutually agreed upon goals. For example, in my experience, the nonprofit partner's input can be more impactful on decisions around student support services, versus decisions that 
affect where teachers' classrooms will be located. Appropriate decisions for collaborative partners can be established during the prework stage of forming the partnership, when developing the shared goal or agenda.

\section{Shared Leadership Practices}

Shared leadership can be defined as distributing power to make decisions across members of a group, rather than having a hierarchical structure wherein decisions are made only from the top (Kocolowski, 2010; Lambert, 2006; MacNeil \& McClanahan, 2005). In terms of school-CBO partnerships, shared leadership practices can interrupt the status quo relationship typical to schools, wherein the $\mathrm{CBO}$ s are subordinate to the schools. At a school site level, sharing leadership means that instead of the principal making unilateral decisions, $\mathrm{s} /$ he has team members who provide input.

Schools often have many groups with various degrees of connection to each other and to the principal (Kocolowski, 2010; Lambert, 2006; Yaron, 2009). Having worked extensively in several schools, I know that leadership group structures can become extremely complex in an effort to decentralize authority and redistribute decision making opportunities and authority. Models range from a principal working with one small group or a single person, such as his assistant principal(s), to the principal working with several groups that collaborate together, like the Parent Teacher Student Association (P'TSA) and the school site council. Normally at school sites there is a top administration team, a department head team, and various other teams that are designated by area, such as grade level, subject matter, or special needs (e.g., SPED, ESL). These teams traditionally do not include CBO participation, meaning typically, the lead agency partner or Beacon representative would not participate in any of those meetings. 
In my experience, the practice of sharing leadership through processes that allow stakeholders to provide input in decisions elevates their position from being acted upon by the existing power structure, to becoming valued collaborative partners. In the case of CBOs in community schooling, this shift hypothesizes that the community partners can evolve from implementers to co-creators of the school's vision and goals (Epstein \& Sanders, 2006). This change of position may also alter the power dynamics of the partnership. This study will test this hypothesis through examining the implementation of community schools in the San Francisco Unified School District.

\section{Power Dynamics}

I use the phrase "power dynamics" to describe the school and CBO partner's relationship to each other, vis-a-vis the ability to set priorities and make decisions that impact the school community. Collective Impact researcher and practitioner, Mary Jean Ryan (2014) asserts, "Collective impact work requires the creation and activation of new forms of power as well as the use of powerful strategies, tools, and tactics to create largescale systemic change" (p.10). One important element of cross sector collaboration is acknowledging that the parties belong to different sectors, and therefore, shoulder different expectations. Schools and districts belong to the government sector, the sector that provides public services, as well as establishing the laws and policy that the nonprofit and business sector must adhere to. The nonprofit sector is charged with addressing social needs, but is often funded by a combination of government and private dollars. While the CBOs have their own missions, their funding is often tied to student success. Conversely, school funding is not reliant upon working with $\mathrm{CBO}$ partners. This dependence creates a power dynamic imbalance. 
This disparity in power can contribute to feelings of mistrust and frustration, particularly on the $\mathrm{CBO}$ side, which can derail the collaborative partnership, especially in the context of sharing leadership. Within cross sector partnerships, the entity with the least power can feel unheard or overrun. Fears can arise around loss of identity and mission drift (Parker \& Selsky, 2004; 2005). As CBO-school partnerships become more prevalent as a major component of the community schools approach, gaining an understanding of how asymmetrical power dynamics function will be imperative. This study explores how power dynamics influence the equitable integration of $\mathrm{CBO}$ voice, especially when the partners collaborate through creating a shared agenda and ensuring their partnership operates with shared leadership.

\section{Methodology}

This qualitative study (Bogdan \& Biklen, 2003) used a comparative multi-case design (Yin, 2003) to examine how schools implementing a community schools strategy in San Francisco integrate community based organization representation into their decision making processes. I conducted semi-structured, in-depth phenomenological interviews (Seidman, 2006) with eight subjects, including myself. I also took observational field notes at on-site meetings. These data sources helped me understand how the interviewees understand their positions within their community schools environments (Seidman, 2006). Looking at multiple sites allowed me to compare positions and philosophies, as well as draw comparisons related to the community schools strategy by site and between roles (Yin, 2003).

Each initial interview lasted 45-60 minutes, and if I arranged for a follow up meeting, this second interview lasted 30 minutes or less. I had follow up interviews with 
all but three of my interviewees. Intermediate data analysis undertaken during the interviewing allowed me to generate additional questions or modify existing questions to more accurately address the issues I wanted to explore.

Interviews took place over a two-month period. Principals were the hardest group to schedule because of their extremely limited time availability. Additionally, I observed on-site leadership meetings appropriate to my focus, and read published material on the collaboration or the community schools model for each school, which included their websites and information from the district. Finally, I observed and took field notes at SFUSD's community schools cohort meetings, and at community schools presentations and conferences. These additional data sources were used to triangulate the data from the interviews.

I had the interesting and difficult experience of collecting data from myself, as a researcher/informant. Initially, I struggled to remain objective. However, as I gained an understanding of autoethnography (Denzin, 2014) and auto-interviewing (BoufoyBastick, 2004), I understood that it was more important to be honest. As one of the research participants, I am allowed to give my subjective observations and experiences, in just the same way another participant would. Auto-interviewing originated in historical research as a tool for collecting oral histories (Boufoy-Bastick, 2004). To collect an interview from myself on my leadership experience at one of the community school sites, I wrote over a 60-minute period addressing each of the interview questions, and responded through narrative essay (Bold, 2012). In some ways, the experience was much like using a reflective journal in action research, although data collection on my 
role as leader was focused on one time period to match the interviews I collected from the other informants.

After I completed all interviews, I analyzed the data using two kinds of initial codes: open and descriptive (Saldana, 2013). After surfacing over 130 codes, I entered second round coding to revisit the codes and extract themes by developing and comparing word tables (Yin, 2003). Word tables were also helpful for bringing out nuances in the data. To further consolidate the analysis, I compared sites, and then compared responses by role: principal, community schools coordinator or Beacon director, and lead agency. Through these combined processes, I narrowed the codes down to 12 broader categories, then re-analyzed those until I was able to reduce to four emergent themes.

\section{Role of the Interviewer}

I have been engaged in community schools work for more than five years in San Francisco. Further, I have been active in the local community schools cohorts as well as nationally with the Coalition for Community Schools. I co-facilitated the Community Schools Coordinator Network, a national network of community schools professionals who share resources and promising practices. As part of that work, I co-organized the pre-conference for the last two Community School Forums. I've also spoken at several conferences and have written articles. Consequently, I was familiar with all of my interviewees, and all of them knew me, at least professionally. Most of the time, our prior association made it easier to talk because we already shared a certain amount of trust. However, our collegiality also meant that I had to be very careful not to share too much of my own experience, and needed to avoid providing overly supportive feedback 
to their responses in ways that might influence the progress of the interviews (Seidman, 2006). I also had to keep our interviews on track, to avoid going beyond the 60-minute limit.

\section{Participants and School Contexts}

I chose to do a comparative case study to explore how different community school configurations (Warren, 2005) equitably integrate the representation of community based organizations in their leadership structures. I wanted to explore the different community school configurations in San Francisco, including schools with and without Beacons, and to have representation from all three levels of K-12 schools: elementary, middle, and high school. (See Table 1.).

Table 1. SFSUD school sites selected for data collection

\begin{tabular}{|l|l|l|l|l|}
\hline CASE & $\begin{array}{l}\text { GRADE } \\
\text { LEVEL }\end{array}$ & $\begin{array}{l}\text { COMMUNITY } \\
\text { SCHOOLS } \\
\text { CONFIGURATION }\end{array}$ & NOTES & \\
\hline 1 & Elementary & $\begin{array}{l}\text { Principal } \\
\text { Community schools } \\
\text { coordinator } \\
\text { Lead agency }\end{array}$ & $\begin{array}{l}\text { One of the first schools to } \\
\text { implement the community } \\
\text { schools approach. Recognized by } \\
\text { the Coalition of Community } \\
\text { Schools as exemplary }\end{array}$ & Former SIG funded school \\
\hline 2 & Middle & $\begin{array}{l}\text { Principal } \\
\text { Community schools } \\
\text { coordinator } \\
\text { Beacon Director }\end{array}$ & $\begin{array}{l}\text { Principal } \\
\text { Beacon Director }\end{array}$ & My own site \\
\hline 3 & High school & & \\
\hline
\end{tabular}

Accessing a pool of schools for the study was not difficult as I am a part of SFUSD's community schools cohort. I first asked for volunteers, the only caveat being that the school and its lead agency partner and/or Beacon self-identify their level of 
commitment to their partnership as "engaged" (Hill, 2011), or highly dedicated, at least. I also wanted to study one school that had a Beacon director as well as community schools coordinator to explore how those positions worked together at a site. That process yielded three schools, all of which have a highly functional relationship with their lead agency partner.

\section{Importance of Community Schools Leadership Roles and Interplay}

Mark Warren (2005) highlighted community schools role configurations. He determined that the community schools approach had three models:

1) the social model - covering full service community schools and such formations as the school district employees head the implementation process or school district staff partner with a CBO lead agency to implement the process; 2) development model or charter schools; and 3) the organization model - a community advocate manages the process. (p.139)

The configurations and roles are important because they help determine the overall structure of the collaborations. This structure impacts access to decision making processes and practices, which affect the level of inclusion and input a partner could have.

The importance of principal leadership in the implementation of the community schools model cannot be understated (Crosby \& Bryson, 2006; Dorado et al., 2008; Business Higher Education Forum, 2009). Principals play an essential role in the prework of cross sector collaboration (Bryson, Crosby, Stone, \& Saunoi-Sandgren, 2009). When the principal, as lead decision maker on a school campus, is invested in the successful collaborative process, it is easier to get buy in from the other stakeholders. The principal works in conjunction with various decision making bodies, 
yet has the final say on most decisions of the school. Thus, his or her buy in to the community schools strategy often paves the way for successfully implementing the approach. Conversely, lack of buy in can condemn the process to struggle or failure (Bryson, Crosby, Stone, \& Saunoi-Sandgren, 2009).

While the principal focuses on the big picture, the community schools coordinator is the glue that holds the community school strategy's components in place, as well as the gas that keeps the engine moving (Dorado, Giles, \& Welch, 2009). To take an example from my practice, during a Beacon/District retreat for Beacon directors and community schools coordinators, we were able to discuss the similarities and differences inherent in our roles. We found, and this has been true in my experience outside of SFUSD as well, that the community schools coordinator often has a wide variety of duties. It may be her job to manage the $\mathrm{CBO}$ partners, mediate between entities with disparate agendas so that they align with the school's needs, and bridge the communication or opportunity gaps between partners and the school. She may also be tasked with overseeing the school's collaborative process on the ground, including sitting at a variety of leadership/decision making tables as the liaison for outside partnerships. The community schools coordinator can serve as voice for $\mathrm{CBO}$ partners by gathering their input, as well as being the school's conduit to its CBO partners to deliver feedback. If the community schools coordinator is a district employee, she has easy access to student and family data, which are imperative for creating informed and responsive programming. In contrast, if the community schools coordinator is not employed by the district, he or she cannot easily access school data, due to confidentiality laws. Furthermore, community schools 
coordinators who are not district employed must cultivate relationships as an outsider to a school ecosystem.

The lead agency partner is usually the school's most active nonprofit partner. An example of a lead agency partner would be the YMCA or the Boys and Girls Club; it is usually a nonprofit community based entity. Lead agencies often have staff on site full time to run programs; typically these are afterschool activities, mental health services, or a combination. The lead agency partner leadership can be the $\mathrm{CBO}$ representative at the school's decision making tables, representing its concerns and the interests of the parent engagement and support services partners. Lead agency partners often represent the voice of the outside entities that have a close relationship to the school.

For this study, Beacon Directors will take on the community school coordinator role, the lead agency partner roles, or both, performing many of the aforementioned duties in the previous paragraphs. They also have their regular Beacon duties such as supervising staff, fulfilling contract and funding requirements, fundraising, and managing programs -- sometimes at multiple sites. Beacon Directors also have obligations to their lead agencies, as well to the San Francisco Beacon Initiative. This multifaceted role can be both a benefit and a challenge.

\section{FINDINGS}

\section{The Three Case Study Sites: School Portraits}

\section{Case 1 - Hillcrest}

Hillcrest Elementary began collaborating with $C B O s$ as an organic solution to the problem of not being able to succeed alone about 10 years ago, Hillcrest has a commitment to making its partners feel valued that starts from the top. Is there a thing as too much shared leadership? 
Hillcrest Elementary School is nestled on a hill in the outer Mission district. According to the San Francisco Unified School District 2013-14 school data, the school's total student population of 446 was comprised of $42 \%$ Latinos, $35 \%$ Asian, $10 \%$ African American students, and a smattering of various other cultures. The API score, one of the references used to rank schools, for Hillcrest was 723 in 2012-13, which is well below district's average API of 821 . Scores aside, Hillcrest, works hard to "ensure a consistently caring" and "welcoming environment" for the entire school community.

Hillcrest's community schools team includes the principal, the community schools coordinator, and the lead agency partner. The principal and the community schools coordinator have worked together for almost 10 years and the interviewed program director of their lead agency partner has worked with the school for 5 years. Participants all told a story of increasing professional responsibility at the site. Prior to his current position the principal was the Instructional Reform Facilitator (IRF), a district position that provides coaching and professional development for teachers. The community schools coordinator had started off as the family liaison, and in that role was responsible for connecting families with schools. The program director for the lead agency began as a substitute teacher at the school, then site coordinator employed by a $\mathrm{CBO}$, then program director at the new $\mathrm{CBO}$. My initial impression, which was confirmed after interviewing, was that they are a tight knit and coordinated team, who are committed to the school and community in their individual positions, and as a team. They demonstrated this team approach by how they defined the community schools model. 
From interviews, I understood that the school has been implementing the community schools strategy for close to eight years. Originally funded by a Healthy Start grant, the administrative team began implementing the strategy without the benefit of any formal introduction to the framework. The community schools coordinator described the environment as desperate, "The climate of the school was so bad. Teachers were yelling at kids in hallways. Kids were constantly out of class. There were fights on the yard. I mean it was just not only not safe; [it was] just not healthy." As a group, they instinctively understood that to improve the prospects of success for their students, the school would need more help, particularly from community based organization programs. Since that time, Hillcrest has fully adopted community schooling as a reform strategy philosophically and on paper. The concept figures prominently in the school's literature and on its website. It clearly describes the school's definition of and connection to the strategy saying, "We are a community school that focuses on five core elements: a rigorous, student-centered academic program; enriching afterschool and summer programming; physical and mental health services for students and families; family support and engagement; and community collaboration" (SFUSD, 2014). Spelling out the concept on the website and in school literature, including on the school's balanced scorecard, provides some evidence that strategy is ingrained in the school culture. It also suggests that the approach is more permanent than temporary. Additionally, they prioritize the strategy through funding choices. According to the principal, "When we get down to budgeting, the last few years we've talked about - we budget things for our community school focus." The prominent position of the community schools approach is 
indicative of the level of integration and maturity of its implementation at this site. The other schools, including mine, have not reached that level of integration, just yet.

According the principal and community schools coordinator, the school was one of the lowest performing schools in SFUSD about a decade ago, with all attendant issues that usually accompany low student achievement. They knew they needed a real change to facilitate student learning, and as the saying goes, "Necessity is the mother of invention." They wanted to turn the school around and had a tight budget. The community school coordinator explained, "We started to look for partnerships. We started to look for folks to help us with mentoring and tutoring and started to acquire these partnerships with different community-based organizations without realizing that it was anything, that there was a name for what we were doing, really." Operating without any structure for their collaborations with the community, they began to look for partnerships that could fill the gaps the school was unable to handle. Three years later, New Day for Learning chose them as a flagship school (as they did for my school, Burton High) and helped them to begin to systematize their collaborative efforts by using the community schools approach.

\section{Case 2- Everett Middle School}

This bustling middle school already had a Beacon Center on site, and because of the School Improvement Grant (SIG) funding, also hired a community schools coordinator. But then a new principal was hired. How does the integration of $C B O$ representation work when there are two members of the community school leadership team combined with a change in school leadership?

Everett Middle School, with its beautiful Spanish style architecture and inviting outdoor courtyard, is located on the edge of the Mission and Castro Districts. SFUSD School Data Report (2013-14) indicates that in 2013, the student body of this sixth 
through eighth grade school was made up of 437 students, over half of whom identify as Hispanic. The Other White and African American populations measure $15 \%$ and 14\%, respectively. Asians comprise close to $8 \%$ of the student body. The last API score recorded for Everett was 728, well below SFUSD's average score of 807 (2013). Based on CST scores, Everett was identified in 2010 as one of California's most persistently low achieving schools. However, with the support of high functioning collaborative relationships, the school has experienced significant growth in each year since.

According to SFUSD's Strategic Plan (2010), San Francisco Unified School District received a three-year grant to support several low performing, high needs, schools located in two of the city's most economically challenged communities, Bayview and Mission. SIG (School Improvement Grant) funding was awarded to Everett as a part of the original schools in the Superintendent's Mission/Muir Zone. With the money, those schools were supposed to implement the community schools model, and therefore, needed to hire a community schools coordinator. Funds were also allocated for technical assistance and support for areas such as parent engagement and afterschool activities.

From 2010-13, Everett's community schools implementation helped the school make steady progress, which could be attributed to the school staff's efforts to coordinate services and develop meaningful partnerships. The community schools configuration consisted of the principal, the community schools coordinator, and the Beacon director as lead agency partner. The principal at that time had a reputation for being dynamic and attentive to the school community activities and its partners. He was a strong proponent of the community schools approach and of Beacons. The community schools coordinator was a well-known, long time, community activist who would now be working as a 
district employee, which would seemingly constitute an almost 180 degree change in perspective. Finally, the Beacon director had been at Everett for three years by 2010. The Mission Beacon had a reputation as a social justice/community activism-focused program that sometimes seemed to be at odds with the school or with the San Francisco Beacon Initiative. The Beacon director and her lead agency had to fight more than once to remain the stewards of the Mission Beacon at Everett.

In the 2013-14 school year, the assistant principal was promoted to principal of Everett. At the same time, Beacon funding was up for renewal. Through the RFP process, the site was refunded, however, that lead agency and the Beacon director were dismissed. This act brought up issues around power and agency, especially as it relates to school/Beacon relationship.

\section{Case 3 - Burton High School}

Burton High and the Bayview Beacon: a love story. Literally and figuratively a journey from old school to new school.

Burton has always been in the middle of reform. Its founding was as a result of a consent decree ruling where the NAACP had sued SFUSD for racial discrimination and the resulting ruling had required SFUSD to desegregate its schools, among other things. Today Burton is one of San Francisco's most diverse schools. This current school year of 2014-14, there were 1028 students attending Burton. Student demographics were $35 \%$ Asian, 23\% Hispanic, $20 \%$ Filipino and 11\% African American. We also have 5\% Samoan students, which is the largest percentage of Polynesians in the city. Our API score was 724 , well below the district's average. About $59 \%$ of our students qualify for free and reduced lunch. 
Local San Franciscans never believe it, but Burton is in the Portola, rather than the Bayview District. Therefore, inasmuch as the majority of our student population's families are economically challenged, the neighborhood residents where the school is located are not. That mismatch always brings up an interesting dilemma when attempts are made to involve the school's neighbors in the decisions of the school. Such neighborhood involvement in decision making is the practice of some who implement the community schools model. This mismatch between the neighborhood and the school population this makes it even more imperative to connect with $\mathrm{CBO}$ s rooted in the communities where the students live, including the Bayview, Mission, and Excelsior districts.

In 2009, I took on the position as the director of the Bayview Beacon (BVB) at Burton High School (BHS), which means that in the year of this study, I was in my fifth year of leadership there. Beacons have been in San Francisco for 20 years. Currently there are eight neighborhood based Beacon hub sites, covering about 20 schools. The Bayview Beacon had moved from its original school because it had closed, and so Burton was its second home.

When I arrived, I found out about Burton's history as one of San Francisco Unified School District's premier high schools, although that had been some time ago. In recent years, the school had begun to hemorrhage students. In 2003, there were 1600 students crowding the hallways. By 2009, there were fewer than 800 and the district had moved another school into the basement. Burton had lost its reputation for being academically rigorous and gained notoriety for fights, gang violence, and low prioritization of academics or college-going culture. Burton was in 
trouble, yet I found most of the staff to be committed, especially the principal. He was smart, funny, and blunt. It was clear that he really cared about the kids from the personal relationship he seemed to have with each one. He had been at the school for four years and had been the principal for two. In our early conversations, I found out that he had lived and taught in Washington, DC, where I am originally from, and that a one of his mentor/principals had been one of my favorite English teachers in junior high. I knew we would get along well.

In my first month, Burton was chosen to implement the community schools model, which encouraged us to begin looking at the notion of deeper and more impactful collaboration. Early on, I realized that both my Beacon program and the school had similar goals, such as higher graduation rates or lower dropout rates; however, our attempts were often isolated efforts that resulted in outcomes not necessarily connecting to a larger, more comprehensive, co-created design. Thus began the relationship that I have likened to a marriage in my previous paper (Hill, 2011). That is, when two distinct entities decide to join with the goal of building a successful life together.

\section{Cross Case Comparisons}

Becoming a Unit: Prework and Common Agenda

Schools and $\mathrm{CBO}$ programs generally have similar goals, although their priorities may vary depending on factors such as funding obligations or personnel bandwidth. As discussed earlier, the co-creation or development of a common agenda is a way of establishing and maintaining common ground among the individual parties. The shared agenda, also referred to as mutually agreed upon goals, is imperative to building stronger 
relationships within the context of cross sector collaborations, particularly between a school and community based organization (Kania \& Kramer, 2011). It is the part or the collaboration process that is known as prework, the time and effort designed to ensure that partners begin their collaborative relationship and process on the same page at the beginning of the collaboration process. Ideally, it is at this point that common goals are developed, and partners decide how they will work together to achieve them.

Among the three sites, the community schools teams of Hillcrest Elementary and Burton High expressed that a clear vision of shared agenda as central to their strategy for community schooling and resulted in their respective teams working better together as a unit. The members of the middle school team implied a shared agenda but without collective agreement, their collaborative relationship and efforts were strained. This section will trace contrasts among the three sites by examining the development of the common agenda, taking place through evidence of "prework" (Crosby \& Bryson, 2006). It will provide examples of the two components of shared agenda described by Kania and Kramer (2011): shared understanding of the problem and a mutually agreed upon common solution. If the goal is to have separate entities work as a cohesive unit, the stronger the quality of the partners' prework, the stronger the alignment of the collaborative relationship.

Prework

Prework sets the foundation for strong and functional relationship that is necessary for success, particularly in cross sector collaborations. In addition to creating mutual agreements together at the beginning of the partnering process, partners also determine which decisions would be most appropriate for the $\mathrm{CBO}$ partner to have input. 
The quantity of time does not seem to be as significant as the full participation of each entity in whatever time they share. Engaging in this process cultivates buy in and trust working as a unit, embracing their individual obligations and differences, rather than ignoring them.

All three sites participated in some measure of a prework with notable differences and results. For example, the elementary school had the unusual experience of having a long prework period that had a positive influence on the strength of their collaborative relationship.

With the Healthy Start grant, you had to do one to two years of planning, and actually we did it in one year ... We met regularly and they helped you walk through this assessment process, and you'd have work plans and you have to really have stakeholders and all the different areas participate. So, that helped us work better together. It helped us get the frame and to set and reach our goals. SE, $1 / 10 / 2014$

Having this time set aside and paid and by focusing on a shared goal allowed the Hillcrest team to strengthen their bond as partners. By the time the grant sunsetted, the principal, community schools coordinator and the lead agency partner had established the community schools team structure and consistency that is foundational for a strong collaborative relationship.

Similarly the Burton team, which consisted of the principal and me, also participated in a prework process, although it was significantly less formal than the one Hillcrest undertook. Still, the results were analogous. Our prework started with us both developing buy in to the community schools concept, which neither of us knew much about. Over the course of several months, I went to conferences, read books and articles, and had technical assistance coaching. Concurrently, the principal did an internship with the Children's Aid Society, the pioneer agency focused on community schools work, 
under the supervision of community schools expert, Jane Quinn. With better grounding in the community schools strategy, we were able to develop mutually beneficial goals through a series of meetings and retreats, and both formal and informal communication strategies. In addition to administrative and department head meetings, we used all modes of communication available to connect, including phone calls, text messages, emails and hallway crossings. Sitting together in a room was not always convenient for us, but consistent and efficient communication was foundational in building trust. In one of our meetings, the principal essentially invited me to be a full partner with him, with voice and vote at the major decision making tables of the school. If we were in a romantic relationship, that moment is akin to "popping the question." My "yes" solidified our agreement to set goals together, respective of our separate and collective obligations; to share resources in a way that supported both the school and the Beacon; to be thought partners particularly for decisions that could involve Beacon resources, but not limited to that; and finally, to work problems, issues and failures as a team (Hill, 2011). That shift moved our partnership buy in level from casual to fully committed.

Everett had time and opportunities allotted for prework; however, all parties did not participate. For example, the school organized a retreat wherein the important stakeholders, including the school's administrative team and the Beacon director were invited to team build and discuss goals, but the Beacon director did not attend. Her absence from that retreat, combined with having missed other opportunities to collaborate, seemed to contribute to the feeling that the Beacon and its director were not interested in working as a unit with the school. That conclusion ran contrary to the Beacon director's reasoning. She thought that in terms of capacity and efficiency, she 
could not attend those meetings and meet the obligations of her program. Also, since the community schools coordinator was present at those meetings and events and they met regularly, she was confident that the coordinator would be able to contribute on her program's behalf, making her physical presence unnecessary.

In the beginning of the year they have a two day staff retreat, I think that's crucial to be at because it sets the tone, it sets the foundation, it sets the relationship starting. But I couldn't ask my staff to be there and I knew that I couldn't be there, because it was the beginning of the year and we had to use those hours to plan our program. But I always feel grateful for being asked...I think that knowing that I can go to any table and be welcomed is really all I need, really. I am at certain meetings. So let me just say this because I'm not necessarily available when they're doing staff meetings or when they're doing professional development there are other avenues in which I connect with the school day. There are other tables. VT, 1/8/14

However and unfortunately, while the Beacon director felt her presence was not mandatory at meetings and the retreat for her to feel connected and integrated into the fabric of the school, the school staff saw her absence as a lack of investment in a relationship, of which the community school coordinator, in particular, was carrying the brunt.

I think she's totally present for the afterschool program and the Beacon...But for me to pull her out of that afterschool time non-negotiable with her. She will very rarely do it. I'm fighting with her all the time. I'm saying the school has already met halfway and you're not meeting that last few steps to build a reciprocal relationship. Then I'm looking at the structure. So I meet with her weekly too, and I'm looking at the structure, so I'm kind of translating everything from the school to her, and she's giving me input and I'm taking it back. But it could be that she's there at the table... It could go back to being us and them. I kind of glue us together. Like they trust me, the school trusts me so if there's an issue, it's on me to mediate and that shouldn't be. It should be all of working it out together. TB, $1 / 8 / 14$

Everett's prework process can be described as layers with points of intersection.

The principal had her administrative team, which consisted of her assistant principals and 
herself, which seemed to her core decision making team. She met regularly with the community schools coordinator, as well as with the with the Beacon director, who is in the role of the lead agency partner. However, there was no formal community schools team so they did not often meet together as a unit. Rather, the community schools coordinator acted as a support and bridge from the principal to the partners, including to the Beacon director. This posed a dilemma because the issues arose that perhaps could have been avoided, had there been agreements reached at the beginning the collaboration. However, principal, community schools coordinator and Beacon director never agreed on how they would work together, which resulted in frustration and distrust between them.

\section{Shared Understanding of the Problem}

All three sites have had processes for recognizing what issues were important. The process of coming to a shared understanding of the issues usually involved meetings and retreats, and some form of data. The leadership team used a range of data for decision making. These data across cases included anecdotal, such as stakeholder experiences and word of mouth, or empirical, employing a formal assessment tool.. At times, both means were used simultaneously or one after the other. Though each school had some way of agreeing about the problems, there is the issue of buy in that is salient in order to ensure that each member of the collaborative team agrees that the problem(s) that they have identified is the one that they will all prioritize to solve together. Both Hillcrest and Burton underwent a successful process to identify problems that the school, lead agency partner and the Beacon director agreed to work on. As a result, there was a stronger feeling of team cohesiveness, as well as the partners feeling that their input was valued. This increased the sense of belonging and trust among the groups 
For example, initially, in 2006, the principal, lead agency partner, and community schools coordinator at Hillcrest decided to address an issue that they agreed could be better aligned with the school's goals.

We also started to get very intentional about our after-school programming and really work more closely with our lead agency there and really understand the budget and really start to make some request about how things were done and try to grow the program. So just based on the need of the community, we really started. But there was no real needs assessment. It was just based on our own understanding. SE, 1/10/14

Latin 2008, they were able to do a formal assessment including the lead agency partner and the results were different. "So through that, we did a needs assessment and really chose the areas of family engagement out of school time and wellness as the areas we really wanted to dig deep into..." SE, 1/10/14. Once the team was established, they used an assessment tool to come to 3 priority areas, as a team. A product of having the time and tools to come to a shared understanding of the issues was an increase in trust and investment in their relationship, grounded by a common focus. The Hillcrest community school coordinator describes the process thusly: "The benefit was that there has been time for building mutual respect, to get buy in and the way that sometimes you need to when everybody has separate obligations that they have to meet" SE, 1/10/14

Though the principal believed strongly in alignment as a tool for focusing collective effort, the Everett partners did not always identify a problem to solve together because, as we saw in the prework section, all partners were not fully engaged in the process. As a result, the principal and community schools coordinator often found themselves at cross purposes with the Beacon director, both doing important work but still siloed. At times, the principal wanted to focus an issue, which did not align with the Beacon director's top priority for distribution of her resources. Though both goals filled 
a genuine and important need at the site, the fact that they did not always identify a common issue together increased the partnership misalignment and translated into ineffective communication according to the principal. She said,

One of the challenges can be that there are so many good people, smart people, passionate people working to help a group of students who absolutely need help and deserve help. And sometimes people are working, and they're not quite aware of what everybody else is doing, and so their efforts aren't streamlined and kind of aligned as much as they could be. And so that's something that I think a really, really highly effective community school has acknowledged that that's the case and said, "Okay. What is our communication flow, so that we're all kind of working with the same goal in mind and with the same knowledge?" $\mathrm{V}, 1 / 8 / 14$

While this lack of alignment and communication issues was problematic for Everett's principal, the Beacon director saw it as less of a hindrance. Though they did not agree to work on a problem collectively, the Beacon director felt that their working in tandem was effective. She rejected the need for alignment in favor of integration. As an integrated part of the school, the Beacon director was able to retain her independence and identity as a CBO program, while still addressing the pressing needs of the students' families and community. The issue was that her relationship with the principal suffered, as well as their ability to pool resources, because they were not always on the same page.

\section{Mutually Agreed Upon Solution}

Though it may seem obvious, particularly after groups take the time to identify a problem, that partners would also decide on solutions to address the issue. Identifying and agreeing on the issue to be tackled together is only part of the process toward creating a shared agenda. Determining a common solution and how the partners will work together to accomplish it, is the other component. The mutually agreed upon solution is critical because it facilitates further partner cohesion and connection toward accomplishing the shared goal. It is at this point that leveraging 
resources comes into play as partners must take into account factors such as funding and personnel hours, which already may have been allocated before the parties had decided to work together. All parties agreeing to a solution might help decrease misunderstandings around the use of funds, time, space and manpower. Absent a unified and agreed upon solution, the remedy to the common problem is open to interpretation, which provides opportunities for partners to do what makes sense for them as individual entities, versus for the good of the collective. Decreasing misunderstandings often leads to increased trust.

While both Hillcrest and Burton identified a shared issue, only Hillcrest determined a common solution that was attached to a measurement of success. Hillcrest was the only school to consistently complete both components of the shared agenda process. They had a process that included the important stakeholders and had meetings to ensure that the parties had input and buy in in both components. The result was the ability to move the needle at their school in such areas as family engagement and partner collaboration.

Conversely, the Everett team was not always able to get buy in on a problem, nor did they come to a mutual agreement on a solution. There were times when the Beacon director agreed to address the same issue as the school, however they did not reach a decision on the common solution. For instance, the schools wanted to work on behavior by doing push ins, which involves staff going into classes to work with students, rather than pulling students out. In contrast, the Beacon director felt that a better solution would be to give the students more basic forms of help, such as food. She thought her limited time and bandwidth might be better used to do more proactive support around providing a 
safe space that included food, rather than releasing staff to go into classes for that reason during instructional hours. In this example, the partners had a common focus, but the lack of common solution rendered their collective efforts less effective. Sometimes the Beacon director was willing to compromise, especially when she felt that obligations were being acknowledged and respected. Her program was often strapped for manpower and hours, but she found ways to broker win-win solutions that created synergy between the school and her program. For example, the school needed lunchtime coverage. Teachers were contractually unavailable and most Beacon staff got in too late. The Beacon director felt that she had a real choice.

So the community school coordinator does lunch supervision. So they wanted the Beacon staff doing lunch supervision as well, and I'm like, "Okay first of all, my staff doesn't come in early enough." So I pushed back on that but then I came to terms with it and I said, "Okay, I want to be a team player, I want to be supportive." So what I promised that either I or someone would be there at 12:30, the school promised they would send one of their security guards there, and then I said that my staff would then be able to come in around 12:45 to help out and to get the kids ready for field trips or whatever. I mean it was really to our advantage anyway. But I was given this space and the respect to push back to the principal and to the community school coordinator. And then I thought about it and I was given time to let it sink in. It wasn't a directive, it wasn't a mandate. It was room for compromise. So, I got that, and we do it and now we're cool. VT, $1 / 8 / 14$

Burton's process fell somewhere between Hillcrest's and Everett's. For example, the leadership team (included myself) at Burton understood that over 35\% of the seniors who graduated did not immediately enroll in college and that there was very little support for them to make alternative post-graduation plans. We agreed that a solution would for Beacon and the school to combine funding to hire an employment specialist for those students. However, we did not agree on how we would determine success. In other words, there was no plan established that would map to a particular outcome (e.g., 
number of students served) beyond hiring a specialist. As a result, the Beacon served over 200 students. However, only 15 of those students were of the population of seniors not going on to any form of higher education who had been originally identified.

\section{Shared Leadership}

The previous section offered a fuller understanding of how schools and CBO programs use prework for setting a common agenda in order develop cohesive collaborative relationships. Partners evolved from completely separate entities, into cohesive partners tied together by a shared agenda. This section will examine how shared leadership practices advance a partnership from casual to fully committed to making decision together that would address their shared agenda. This section will also help investigate the research question of the equitable integration of community based organization voice in leadership structures of a community school.

In order to shed light on the practices, I explored the decision making bodies of the schools, the role of the principal and how (whether) the CBO partner feels and is included. My contention is that there has to be a leadership structure that can expand to embrace an (often) outside partner. Along those lines, the principal has the most significant role in assuring that she or he distributes decision making power, extending it to the lead agency partner or Beacon director as well. If the principal decides to share leadership and decision making, the school will follow suit. As schools and CBO programs increase the quantity and depth of blended resources within the community schools strategy, there should be appropriate emphasis place on shared decision making power as well, particularly for the $\mathrm{CBO}$ partner. With this expansion of their role in 
decision making, partners feel integrated as a more permanent and valued member of the school community.

\section{Decision Making Structure for Shared Leadership}

Shared leadership practices look different at each school, but all of the school site principals, community school coordinators and lead agency partners affirm that their leadership and decision making processes are inclusive, rather than top down and authority driven. This inclusivity begins with access to the highest decision making table, typically the administrative team meeting. Burton and Hillcrest have similar formal leadership structures. They both have administrative teams and weekly meetings that regularly include the principal, assistant principals and the community schools coordinator (lead agency partner or Beacon director). Having a seat at these decision making tables seems to have been a vital part of the community schools strategy for these schools, and contributes to an inclusive environment.

Everett's top administrative team includes the principal and her assistant principals only. That is not to say that the community schools coordinator and Beacon director do not have access to decision making tables. As was previously mentioned, the principal meets weekly with the community schools coordinator and monthly with lead agency partner/Beacon director. Also previously established is the symbiotic nature of the relationship between the community schools coordinator and the Beacon director, albeit rather problematic for the community schools coordinator.

\section{Role of the Principal in Sharing Leadership}

As the ultimate authority at a school site, the principal has a crucial role in establishing inclusive leadership practices. If the principal espouses shared leadership 
practices, the rest of the staff would adopt group decision making as well. All of the community schools' principals in these cases say they believe in sharing leadership for the most part. One principal explains the exceptions of when shared leadership is less easily practiced.

At Hillcrest, each person interviewed talked about the principal's distributive method of leading and making decisions. Apparently, it is a long standing tradition at this school, starting with the former principal and now with the current. The principal said, "I believe fundamentally that every teacher and staff person has something to bring to the table. So I make sure they have leadership opportunities, especially my afterschool director [lead agency partner].” RZ, 1/3/14,

Similarly, the principal at Burton was putting collaborative decision making policies in place before the Beacon arrived. He said "Burton is a highly collaborative place, which is why it was fairly easy to ask Carol.” As I mentioned previously, while I was establishing my Beacon and operating as if the principal and I would have a more separate relationship, he invited me to become a full partner - a creator versus an implementer - as it relates to decisions around integrating the priorities of the school with those of my program. This new position allowed me to transition from feeling like an expendable outsider to a valued member of the school's team.

The lead agency partner of Hillcrest had a comparable experience. He felt absolutely embraced as a member of the administrative team because the principal made sure he was included. The principal and community schools coordinator established that the lead agency partner would be at the primary decision making tables by inviting his predecessor; he is extremely confident in his position as a fully integrated member of 
Hillcrest's leadership team. He feels so assimilated that he and the principal consider his staff and him as part of the Hillcrest team, who happen to be paid by an outside organization. In fact, he has been a part of the discussions that concern keeping his lead agency. If the administrative team (including him) decides change lead agencies, he is confident that Hillcrest will require that new entity to hire his staff and him. As a member of the administrative team, he feels that his input is valued and that his priorities are completely aligned with those of the school. He also would take it upon himself to help a new nonprofit partner understand the "Hillcrest way," should the school switch to another organization. He said,

And in that change, I'm looking at it as it's a process of integrating into the new CBO. At the end of the day I'm still Hillcrest, you see what I'm saying? But I'm now bringing in a new $\mathrm{CBO}$, and I needed to make sure that our -- the way we do things at Hillcrest is transferred over and has a good synergy with the new CBO. And so they were part of all the negotiations, all of the hashing out details of how these two bodies would integrate. And so the community schools coordinator -and she helps me with planning and [is] a good second -- a good eye, because I don't want to just be -- you know, oftentimes the CBO's interests are not necessarily the school's interests. J, 1/21/14

As I mentioned, the new principal at Everett believes in sharing leadership, but is also committed to setting the priorities of the school and making sure they are accomplished. That means that at times, she sets goals without input. She said, I think, for the most part, I'll make decisions on my own if it's things to do with what our core values are, or our priorities around English learners. Like, I, as a principal, have worked with our instructional leadership team to set a really clear priority goal around our English learner growth, and that's nonnegotiable to me. That's not something I'm going to really discuss or change right now. And so that's an example of where I'm just like, "That's our priority. That's what it's going to be." LVH, 1/8/14

Clearly this would be problematic under normal circumstances. Traditional schools often function using hierarchical decision making. If a school is implementing the 
community schools approach, shared decision making should be norm. However, not all the time. In fact, this principal's notion is a good example of when equitable integration of $\mathrm{CBO}$ voice makes sense. Both Hillcrest and Burton gave input for our school's core value. However, a question concerning English learner growth might not elicit as useful feedback from Beacon directors and community schools coordinator, as could be obtained from instructional staff. With limited time and energy, it makes sense to start there. Later Everett's principal explained the circumstance under which she would share leadership:

I would relinquish that decision to maybe the community schools coordinator. Or where I would definitely not just insert my point of view and say, "This is what we're doing," would be anything where, once that priority is established, then -- I mean I need other people's input, and I need and I trust the people I work with to make decisions that will be supporting that goal. So, whether it's -- I'm trying to think of one example. Like, an organization that's helping with parent education, for example. I'm not going to be the one to say, "Yes, this organization," or, "No, this one," or, "This is how I want you to do it." LVH, 1/8/14

However, it is just this parceling of information and feedback that has contributed to Everett's community school coordinator's feeling somewhat disconnected under the new regime. She felt that the previous principal trusted her implicitly. She was a thought partner and gave input for many decisions, regardless of whether it had direct bearing on her position. And gave her a considerable amount of latitude to do her job. She truly felt that she was a fully contributing leader in the school. His policies fostered trust and connection to the school's priorities. Unfortunately, currently the community schools coordinator does not feel as though she is sharing leadership that much anymore. She is managing many tandem connection, including with the Beacon director, but does not feel the integration that she used to. 


\section{Institutionalized Shared Leadership}

Aside from the normal School Site Council (SSC) that most schools have, which includes school staff, students, parents and $\mathrm{CBOs}$, the Bayview Beacon sits at the major decision making table with the principal and vice principal, as well as at the table with the department heads. The principal summed up his reasoning for officially integrating the Beacon into the school leadership structure thusly:

I mean it seems to me that if we really wanted to embrace the tenets of the community school model, we really should embed The Beacon in the larger structure of the school. So, at that point, we've embedded her. We were like, "We're going to treat her as a member of the Administrative Team." So, she came to our administrative meetings twice a week, and then she went to our Leadership Team meetings once a week... But I do think, in the founding years of The Beacon, it was really important that she -- or, that the Beacon director had an opportunity to sit in on those meetings... to make sure that we didn't overlook The Beacon; or, take them for granted; or, make sure that, you know, when an opportunity arose, it didn't get lost as a really great idea at that table. BK, 1/22/14

Because I am a member of these bodies, I feel that I have the opportunity to give them feedback that they would not otherwise get from a partner. My input is considered and often acted upon. I know I am valued as a partner.

As the non-district representative, often I am the person who brings the concerns of the community, students and parents directly to those the tables each week. The Beacon has also been integrated within the school's fabric going as far as be included on the school's balanced score card.

On the most surface level is that the Beacon is actually embedded in our balanced score card. And the community school's model has been something that we've been, it's been written into our school accountability plan for several years, even way before the district had started to require all schools to add some verbiage on how are they moving closer and closer to a community school model. And even in our balanced score card, which is the accountability report plan that we have to submit to both the school district and to the state - we have three key initiatives ...And then the third piece of 
this is adopt and take on the community school model, which means that, you know, build out a robust wellness center and teen clinic, build out a whole host of afterschool, lunch and Saturday activities for our kids to belong to. So, I mean, having said that, collaboration with the Beacon is embedded in our academic accountability plan that's submitted to both the state and to the school district. BK, 1/22/14

The principal talked about how I bring a perspective that sometimes teachers or administrative staff do not have because of their particular jobs within the school community. Frequently, I am one of the bridges in the leadership structure between the policy being made up at meetings and the impact on students and families.

She comes to the meetings once a week, whenever they're scheduled. And the expectation is that she brings her expertise and to leverage her insight as to things that teachers and academic departments sometimes overlook. She brings a certain perspective and skill set that, you know, the History Department chair, or the Math Department chair may get caught up in the details of teaching and learning. And sometimes we get overzealous with, you know, instructional time; and we need somebody to remind us that we have to take care of the whole child. So, whether that means carving time out for fun activities, or whether that means carving time out for relationship building, or whether it is reminding the faculty or the leadership team - you know, the people who run the school - that field trip opportunities and guest speaking opportunities and other non-traditional classroom activities are just as important for all children; and we can't, you know, prohibit, for instances, the kids who are struggling to engage in any of these activities. So, she brings a certain perspective that is really important for us to have. BK, $1 / 22 / 14$

\section{Power Dynamics}

In the cross sector collaborative relationship between schools and $\mathrm{CBO}$ program partners, in particular, the governmental entity (school) has the most power. This is especially true when the nonprofit partner is located on the school's campus, or needs access to the school's students or families to meet contractual or grant requirements. This is the major power imbalance in the relationships in the case studies. Sometimes this imbalance can breed mistrust, particularly among the group that 
has the least influence or authority. That insecurity can make it difficult for both sides to fully commit to process of becoming a unit, and subsequently, to sharing leadership. Initially, I thought it was difficult to get people to talk about power dynamics because they were unsure about how it would be received by the interviewer in our session, and later discussed in the paper. But I quickly realized that many of the informants did not see that there were any power dynamics to discuss. At Hillcrest, the lead agency partner and the principal both felt that they collaborated seamlessly and that there were no power dynamics to acknowledge. The fact that the principal has the right to dismiss him from the campus, notwithstanding. According to the principal,

I think both our personality traits are that we are collaborative, so I'm not an autocrat because I don't like to work like that, and I know that lead agency partner doesn't also, so we like to collaborate with each other and talk about what's going on, and the weekly meetings are our time to do that, to just talk about the issues at hand, talk about the finance for the after school program. I don't - ultimately, so the funding kind of helps to define a lot of decision making, so if it's school day funds going to the after school program, I might with this collaboration be able to design something. But again, it has to be filtered through his organization. It's not like I say, this is what I want. It's more of like - I'm thinking this might be a good idea, what do you think about this? RZ, 1/13/14

But he could. Or the next principal after him could, if he or she was so inclined. That is the imbalance in power dynamics that people seem unwilling to unable to own. One of the main consequences of not acknowledging the imbalance is that partners, the school staff in particular, will not work to actively decrease their negative effects.

For example, there is the touchy issue of changing lead agency partners, and what that meant to the Everett Beacon director and the lead agency representative for Hillcrest . When a lead agency agrees to become a part of a school, they normally plan to stay for at least a couple of years, as there agreements for funding, staff and other resources that 
are included in this commitment. Beacon Center lead agencies commit for life, much like a marriage, as I've said.

That said, it follows that changing lead agencies should involve a substantive process, akin to a divorce process. However, that procedure has not been standardized within SFUSD or the SFBI, thereby breeding insecurity for some partners. Conversely, others do not feel it at all.

Case in point, as I have previously stated, a principal can decide to have your program and partnership eliminated. That is what happened to the Beacon director and her lead agency. I do not have confirmation but if I had to hypothesize from my data, I would approximate that the lead agency partner's resistance to aligning with the school goals of the new principal is what why she was eliminated during the RFP process to refund the Beacon at their school sites. I was reminded, as was every other Beacon director that anyone could be evicted. For the rest of the Beacon Centers, the situation highlighted the fact that we are located on a campus at the behest of the principal.

Power dynamics in our cross sector collaboration are always present, particularly for me. That was the case for the other Beacon director as well. I think it has to do with the feeling that our residency can be unceremoniously terminated at any moment. Also, because we are on a school district site and we are still learning how to fully collaborate with each other as government entity and nonprofit, sometimes decisions are made without our input or knowledge. Sometimes, as the other Beacon director from Everett said, we do not have the capacity to attend all of the important meetings that transpire in the school day. At times, this lack of bandwidth is seen by school staff as willful disregard of the school's priorities and efforts to be inclusive. 
Contrary to the somewhat negative light that the Beacon director at Everett, Hillcrest's lead agency partner is $100 \%$ committed and integrated into the school, is so integrated into the school that he considers himself a Hillcrest employee who is paid by a $\mathrm{CBO}$. Although he feels secure, that fact is that none of these positions are ever guaranteed. The Hillcrest, as well as the $\mathrm{CBO}$ management, has the power to dismiss him as well. In fact, it was a fact that Hillcrest was on its second lead agency with my informant. The first organization and Hillcrest had parted ways, but the informant and his staff were hired by the second $\mathrm{CBO}$ to continue to run programs; this was a condition of receiving the agency contract. There was also some indication that the new partner may not work out as well. At Hillcrest, the nonprofit organization may not be on the most secure footing, however the actual person doing the work feels safe, indeed, empowered.

For instance, there was an issue with Newcomer students and their afterschool program needed help with specific qualifications to help this population of youth, They're not telling me, "You'd better hire somebody." They're letting me come up with how I am going to do this. And my actual scheduling program -- I have it highlighted where I have it [?] specifically for newcomer kids. And then I have programs highlighted that have specifically bilingual staff that communicate with the kids. So I feel empowered. J, 1/21/14

However, for the principals in this study, including mine, the issue is not power dynamics issue. The Burton principal felt that there were different agendas, rather than power dynamics at play. That is that every party has requirements or desires that they need to have met. He offered this example:

I see that various groups have their own agendas, and they often vie and try to leverage whatever resources exist in order to get their agenda as paramount to everybody else's agenda. So a couple examples would be, for instance: school health programs have a cookie cutter model for a wellness 
center and they want to retain control over staffing. Whereas my agenda is, I want to have say over staffing, because I have to live with the people who work in this building. I see them every single day. The school health programs people see them once a month when they call a meeting. So it doesn't work for me to simply say, "Okay, if that's your model, we'll have to adopt it." So my agenda is this. I need to have some say. My say is important. And if not, then I can minimize the amount of, I mean not make veiled threats and sometimes they're quite unveiled. Overt and covert ones. And say if I don't get a say then what I'll do is I will make sure that the wellness center's mission is minimized at our school, and I will use other resources like the Beacon, for instance, in order to make sure that our kids' needs are met. BK, 1/22/14

While the principal's example illustrates what it might be like for him to be in collaboration with a district department that has greater power dynamic than he does to affect change in Wellness, he still has the ability to exercise his rights as a principal by minimizing contact with people he was not interested in having around. $\mathrm{CBO}$ partners do not always have that capability.

As a result of the imbalance, there can be a lack of voice. One way to mitigate this lack of voice is with intentionality. The Burton principal genuinely made a point to actively solicit input from all voices at the table. But I do not think it reflects a feeling around power dynamics as much as it is a desire to genuinely know what people think. Even if he does not characterize it as such, he is conscious of the power dynamics in our mixed constituency meetings especially.

So there is a dynamic, there's a couple dynamics that I think you might be alluding to. One of which, just by sheer numbers, the majority of the people sitting around the table are academicians. They're representing academic departments at Burton High School. So like we just said, there's the wellness coordinator and then there's the Beacon Director. Those are the only two non-academic people sitting at the table. So sometimes I feel like, with better facilitation of the department head meetings or the leadership team meetings, we might have an opportunity for more voices to be heard. I find that one, I've been the one responsible for running the leadership team meetings where I'm often planned poorly or I have lots of other things going on, so I don't necessarily think through exactly how I want the conversation 
to go...But I've done this work long enough to know that I can throw out the question and provide everybody with an opportunity to chime in and I will have three very vocal people, and then once they're done talking then we offer it to everybody else at the table. But I think really the reticent people at the table need to remind themselves that they're the leaders, or maybe I need to remind them that they're leaders representing a pocket of teachers or a group of, a stakeholder group that's very important to the school and they need to make sure that their thoughts and feelings are heard on topics. BK, $1 / 22 / 14$

The principal clearly felt that each person at the table has a voice and that it is up to us to make sure we use it. I think he has a point. There is second part to being invited to the decision making tables. Once there, it is important to take advantage of airtime to have a voice and build connection. It does seem to be easier if this principal, like the one at Hillcrest, believes in providing the environment that is conducive to non-district entities feeling included and welcome to share their thoughts.

\section{Discussion}

My assumption was that a shared agenda acts as the glue that connects partners who normally work independently. I saw that assumption borne out with Burton and Hillcrest. I also saw the negative impact of not having a common agenda with Everett. Partners having the time, agreeing on an issue to address, as well as determining the solution for that issue help build cohesion among partners. The deeper the team invested in the shared agenda process, the tighter the connection was among the principal, community schools coordinator, and lead agency. When developing a shared agenda was not prioritized or ignored, the connection of the group to each of the other groups suffered. Mistrust and misgivings among partners increased.

From the teams, I observed that there a need for a shared understanding of a problem and a shared solution. Additionally, these components must be linked to a 
shared vision of success in the form of measureable outcomes. The Burton example of hiring an employment person without thinking through to a mutually agreed upon outcome with the school was almost a waste of money. A shared measurement system is part of the Collective Impact framework. I did not study that condition, but it is obvious why it is included in the framework. Without measureable outcomes, it is difficult to ensure that understanding the problem and agreeing to a shared solution will have the desired impact. Examining this condition should be done as the focus of a further study.

A nuance emerged that I think is worth noting. It is the concept of sharing vs. shared agenda. While almost every person interviewed mentioned having a common agenda as one of the keys for a successful collaboration, who actually creates the agenda, and how, varies. In fact, partners co-creating an agenda together seem to have less priority with the data. It showed that often the school's priorities were set by the school staff, and the CBO partner had to decide how it would support the school's goal. That is actually the traditional way of doing business; failing to actually create priorities and goals together seemed counter to the community schools strategy. I believed that my experience of co-creating a common agenda was so powerful -- wherein I was asked what my priorities were and what goals we could set that would benefit both the school and my program -- that it became a moment that both the principal and I look back on as pivotal and transformational in terms of our separate teams becoming one.

Moreover, I thought that school staff giving the school's agenda and priorities to partners, was a clear illustration of the imbalance in power, particularly if the $\mathrm{CBO}$ partner's priorities were not accounted for. However, while conducting this study, I was able to see that efficiency takes precedence over process quite often and that the 
processes of sharing or co-developing a shared agenda are not oppositional. They both have merit, and can still have the unifying effect.

Discussions about power dynamics surfaced but almost never in the contexts that I thought they would. With the exception of the Beacon directors, everyone else had a more difficult time articulating the impact of power dynamics, in general, and imbalanced power dynamics specifically. I was surprised by that finding. The principal at Burton had some consciousness around how power dynamics might impact voices at the decision making tables, but not the other principals nor community school coordinators, or the lead agency partner at Hillcrest. The literature speaks about acknowledging power dynamics, particularly in cross sector collaboration, the way entities with more power have to invite the entity with less power to the table, and actively solicit input. I think that it is imperative for the principals, especially, to be vigilant about ensuring that all partners not only have fair access to seat at decision making tables, but also a real voice.

Creating a shared agenda, or mutually agreed upon goals, should be done before partners actually collaborate as part of prework. If I could make up a motto for successful collaboration, it would be, "Prework makes the dream work!" After this study, I am convinced that prework is the top priority in any collaborative relationship. Having the time and the conviction to create or agree upon goals, as well as time to decide how to collaborate and what decisions would be appropriate for the Beacon director or lead agency partner to offer input on, it critical. Again, it did not look the same for each site; however, it was important to somehow set aside time to communicate and to fully participate. The principal at Burton and I communicated with the administrative team of the school both formally and informally, modes ranging from 
meetings to texts. Both Hillcrest and Everett had more formal processes, but because Everett did not have full partner participation, they did not reach consensus on the shared agenda. This created fissures in their relationship.

Although Everett did not always shine positively in these findings, I want to reiterate that the principal, community schools coordinator and the Beacon director were all passionately committed to Everett, its students, and its parents. The community schools coordinator was a true bridge between most CBO programs and Everett. She also vetted all CBO programs coming into the school, making sure they were filling a genuine need, while keeping in mind the CBO's priorities. The Beacon director was a pillar to the students at Everett, as well as in the Mission community, known for her fierce and protective nurturing spirit. The principal had her hands full with being a new mom, as well as being new to that position; however, she was committed to being a great principal, following in the footstep of the beloved former principal. If they had been able to embrace the ideas around sharing leadership and the equitable integration of CBO voice together, perhaps they might have worked out their relationship issues before the lead agency partner's dismissal. One result is the heightened awareness that these relationships require a substantial amount of work and maintenance.

How work and maintenance are divided brings up the question of whether it is prudent, when implementing the community schools strategy, to have a Beacon director to double as the community schools coordinator, or whether to have a Beacon director and a community schools coordinator on site. As I've indicated in the first paper, in my experience, conflating the Beacon director and the coordinator position is a mistake, particularly if there are no additional resources available to hire support. Certainly the 
duties are similar, but they are not interchangeable. For example, I still had all my Beacon director directives to complete that were specific to staff supervision/development, grant writing, and I also had up to three other sites that I managed. It was extremely difficult to hold both position at the same priority, and I hardly ever felt that either was getting the attention necessary to be truly successful. When speaking with the Beacon director at Everett, she appreciated the division of duties and made sure she prioritized her Beacon duties. However, the community schools coordinator felt that having both positions was duplicative.

I think the place where the positions were best aligned was at the decision making tables. For me, I could wear two hats easily when speaking about such topics as support services and family engagement to instructional staff. Similar to the coordinator's thinking, it seems that the Beacon director felt that attending leadership meetings with the coordinator was duplicative. She thought it would be a more efficacious use of her time and bandwidth to have the coordinator relay the important points. Of course, being at the leadership table is not about efficiency. It is the act of building relationships and accomplishing common goals. This topic deserves more study to accurately understand the benefits and challenges.

Functioning relationships and trust undergird sharing leadership. There are additional components that positively impact shared leadership practices, as well. For example, the leadership structure of the school has to be able to support outside partners, especially partners from the third sector who have different agendas. For instance, Burton had to expand its administrative team to accommodate the Beacon director. That made my role on the team and in the school more credible. Additionally, the principal should 
set the expectation that each person's voice is important to hear and that all perspectives matter in making decisions. There also has to be a way to ensure that these practices are institutionalized. That can take several forms such as adding the lead agency partner, Beacon director, or community schools coordinator on the school's organization chart. Additionally or alternatively, include the partner or community schools coordinator on the school's balanced score card. It is another tool to establish common goals and shared accountability.

There are challenges associated with sharing leadership as well. Hillcrest Elementary's community school coordinator spoke about the drawbacks of having decentralized power. Often, it proved difficult to make decisions that resulted in action. In the name of efficacy, some decisions were made with whomever was in the room, walking down the hall, or on the other end of the phone. Or to honor the fidelity of the process, no action took place until everyone had had input, which clearly bogged down action. To her, distributive leadership sometimes felt as though nobody was taking final responsibility.

For the Out-of-School-Time professionals at all three school sites, an interesting dilemma arose in the space between being an implementer and becoming a co-creator. It could be difficult to navigate on all sides. The balance in power has to shift and adjust in order to truly share decision making. The next section explores role of power dynamics in shared leadership.

An excellent and clear example of how power dynamics impact shared leadership played out at Everett Middle School. Though both were passionate about the job they did for kids and families, the principal and Beacon director found it difficult to connect and 
collaborate around goals and solutions. From the school's side, the principal saw it as a lack of communication that has led to misalignment. The Beacon director saw herself guarding her program's identity and resources by remaining tacitly connected, particularly through the community schools coordinator. The community schools coordinator seems to be an unwilling intermediary. As a result, the new principal dismissed the Beacon director and her lead agency from the Beacon Center, after they had been working at Everett for almost 10 years. There was no mediation or counseling. Their grant was renewed, but without them as the stewards of the program. In a regular authoritarian and hierarchical leadership structure, principals always have ultimate power on a school campus. If a partner is not fulfilling the needs of the school to the satisfaction of the principal, they run the risk of being dismissed in the same way as the Beacon at Everett was. However, in the context of a community school with a long standing relationship with partners that used shared leadership practices, it seems that there would be more of a process to determine if the relationship can be salvaged. However, that was not the case.

To answer the question, how do power dynamics impact shared' leadership within a community schools team? Imbalanced power dynamic, such as I have just described, decimates shared leadership practices. When the partner with the most power decides to exercise it, the result is that shared and intersecting power ends.

\section{Conclusion}

The purpose of this paper was to look at how schools and nonprofit programs collaborate to build strong, meaningful relationships that eventually solve problems. I hypothesized that establishing a shared agenda as proposed by the Collective Impact 
framework, and looking at power dynamics, while exploring shared leadership practices, would give some insight as to how three schools sites, all implementing the community schools approach, could equitably integrated $\mathrm{CBO}$ partner voice into their leadership structures. My concern was that schools would not be able to effectively share leadership with a Beacon director or lead agency partner, if they were not consciously and actively encouraging their nonprofit partners have a voice in decision making processes, and were not paying attention to the imbalance in power dynamics inherent in cross sector collaborations. The data partially supported my hypothesis.

The importance of a shared agenda and leadership were supported. We saw that school teams that developed a common agenda or mutually agreed upon goals were more cohesive than the team that did not do so. Then partners who were invited to the school's decision making tables felt valued and respected. An outlier was the Beacon director who did not want to become more connected with the school. She appreciated being invited to the decision making tables, but did not feel obligated to go. Whether the results ended up positive or negative, the importance of shared agenda and leadership were not diminished.

My assumption was power dynamics, particularly when they were imbalanced, influence a school and CBO partner's ability to share leadership effectively. This was not necessarily supported. Almost nobody felt that power dynamics played a major part in their shared leadership practices. The exceptions were the two Beacon directors. I thought the other $\mathrm{CBO}$ partner would feel similarly, since as outside agencies, we all had significantly less power to make school decisions. He did not. Overall, my data analysis 
was only able to take a cursory look at this subject. Future research should examine how power dynamics influence cross sector collaborative relationships.

In terms of equitable integration of $\mathrm{CBO}$ representation, I found that the concept that I envisioned was not close to reality, meaning, none of the sites decided what decisions would be appropriate for $\mathrm{CBO}$ partners to be involved in before collaboration. The Beacon director at Everett extended the definition of equitable integration to mean involved on the teams and in the meetings that she felt were appropriate. I did not anticipate that. For future study, I would be more specific. For example, I might design a study that specifically examined what types of decisions are made, when and by whom at the major leadership meetings at a community school.

The third and final paper of this dissertation will offer policy recommendations that could facilitate both shared leadership practices and the equitable integration of community based organization representation at decision making tables of schools implementing the community schools approach 


\section{References}

Blank, M. J., Melaville, A., \& Shah, B. P. (2003). Making the difference: Research and practice in community schools. Washington, DC: Coalition for Community Schools..

Bogdan, R., \& Biklen, S. K. (2003). Qualitative research for education: An introduction to theory and methods. Boston: Allyn and Bacon

Boufoy-Bastick, B. (2004). Auto-Interviewing, auto-ethnography and critical incident methodology for eliciting self-conceptualized worldview. Forum Qualitative Sozialforschung / Forum: Qualitative Social Research, 5(1). Retrieved from http:/www.qualitative-research.net/index.php/fqs/article/view/651/1410

Bryk, A. S. (April 01, 2010). Organizing schools for improvement. Phi Delta Kappan, 91(7), 23-30.

Bryson, J., Crosby, B., \& Stone, M. (2006). The design and implementation of crosssector collaborations: propositions from the literature. Public Administration Review, 66(s1), 44-55. http://dx.doi.org/10.1111/i.1540-6210.2006.00665.x

Bryson, J., Crosby, B., \& Stone, M., Saunoi-Sandgren, S. (2009). Designing and managing cross-sector collaboration. The IBM Center for the Business of Government, 66(s1), 44-55. http://dx.doi.org/10.1111/i.1540-6210.2006.00665.x

Business Higher Education Forum,. (2009). Improving Education Through Collaboration (pp. 1-17).

Children's Aid Society (2006). Summary of the Children's Aid Society community schools results to date. New York, NY: Children's Aid Society.

Denzin, N. K. (2014). Interpretive autoethnography. Thousand Oaks, CA: Sage. 
Dorado, S., Giles, D., \& Welch, T. (January 01, 2009). Delegation of coordination and outcomes in cross-sector partnerships. Nonprofit and Voluntary Sector Quarterly, 38(3), 368-391.

Dryfoos, J., \& Maguire, S. (2002). Inside full-service community schools. Thousand Oaks, CA: Corwin Press.

Dryfoos, J. G. (March 07, 2004). A community school in action. Reclaiming Children . and Youth, 11(4), 203-5.

Dryfoos, J. (2005). Full-Service Schools: A revolution in health and social services for children, youth, and families, San Francisco, CA: Jossey-Bass

Epstein, J. L. (November 01, 2005). A Case Study of the Partnership Schools Comprehensive School Reform (CSR) Model. Elementary School Journal, 106(2), 151.

Epstein, J. L., \& Sanders, M. G. (January 01, 2006). Prospects for change: Preparing educators for school, family, and community partnerships. Peabody Journal of Education, 81(2), 81-120.

Epstein, J. L. (January 01, 2008). Improving family and community involvement in secondary schools - New approaches make partnership programs possible. The Education Digest, 73(6), 9.

Harris, A. (2005). Reflections on distributed leadership. Management in Education, 19(2), 10-12.

Hill, C (2011). Powersharing: Building school/CBO relationships. Afterschool Matters, $14,48-52$. 
Kania, J \& Kramer, M. (2011). Collective impact. Stanford Social Innovation Review.2232.

Kania, J., Hanleybrown, F. \&, Juster, J. (2014). Essential mindset shifts for collective impact. Stanford Social Innovation Review.4-7.

Kegler, M. C., \& Swan, D. W. (2011). An initial attempt at operationalizing and testing the community coalition action theory. Health Education \& Behavior, 38(3), 261270.

Kirsch, L., Braun, H., Yamamoto, K., \& Sum, A. (2007). America's perfect storm: Three forces changing our nation's future. Princeton, NJ: Educational Testing Service.

Kocolowski, M. (2010). Shared leadership: Is it time for a change? Emerging Leadership Journeys, 3(1), 22-32.

Lambert, L. (2006). Lasting leadership: study of high leadership capacity schools. Educational Forum, The, 70(3), 238-254.

MacNeil, A, McClanahan, A (2005). Shared leadership. Connexions, Version 1.2

Ryan, M.J. (2014). Power dynamics in collective impact. Stanford Social Innovation Review.15-18.

Saldaña, J. (2013). The coding manual for qualitative researchers and qualitative data analysis: A methods sourcebook. Thousand Oaks, CA: Sage Publications.

Sanders, M. G. (February 01, 2005). Building bridges toward excellence: community involvement in high schools. High School Journal, 88, 3, 1-9

San Francisco Unified School District (2012, May 8). Teacher layoffs precede, district projects $\$ 83$ million deficit. Retrieved from San Francisco Unified School District 
website: http://www.sfusd.edu/en/news/current-news/2012-news-

archive/05/teacher-layoffs-proceed,-district-projects-\$83-million-deficit.html

Selsky, J. \& Parker, B (2005) Cross-sector partnerships to address social issues. Journal of Management $3 I(6), 849-873$

Seidman, I. (2006). Interviewing as qualitative research: A guide for researchers in education and the social sciences. New York: Teachers College Press.

Warren, M. R. (2005). Communities and schools: A new view of urban education reform. Harvard Educational Review, 75(2), 133-173.

Yaron, J. (2009). Shared leadership - Practice and perceptions of teachers in a virtual community. Unpublished dissertation Hebrew University.

Yin, R. K. (2003). Case study research: Design and methods. Thousand Oaks, CA: Sage. 


\section{Paper 3 \\ Equitable Integration of Community Based Organizations' Voices within SFUSD Schools Implementing the Community Schools Model}

\section{Introduction}

This paper offers policy recommendations that can lead to institutionalization of equitable and integrated community based organization (CBO) voice in leadership structures in SFUSD schools, particularly those that are implementing the community schools model. It posits that shared leadership and shared decision making practices will lead to stronger, more committed outcomes-focused relationships. It also identifies a lack of awareness and acknowledgement concerning decision-making power dynamics as a threat to the health and longevity of these relationships, thereby rendering them less effective in accomplishing the ultimate goal of better serving students and families.

There are several leadership bodies in public schools, but I focus primarily on the community schools team, and those in the positions making decisions about community schools work. Generally these roles include the principal, the community schools coordinator, and the Beacon director or lead agency partner. As partners work toward shared goals at decision making tables within the school, power dynamics should be acknowledged and their effects mitigated. When this happens, then the principal, Beacon director, community schools coordinator and/or lead agency partner are able to cultivate trust and social capital. These resources are needed to withstand the ebbs and flows associated with tackling long-standing and complex educational challenges, such as low graduation and high suspension rates of African American males, poor nutrition, or lack of access to medical and dental care. My recommendations are relevant for the leaders of San Francisco Unified School District (SFUSD) including, the Superintendent, 
Director of Community Schools, principals, community based organization partners, Beacon professionals, and other leaders and practitioners who engage in community schools work.

I write these suggestions as an experienced Beacon director who implemented the community schools approach with a SFUSD school over several years. I have also been active in the community schools local and national discourse, working with the Coalition for Community Schools, writing, and speaking on panels and at conferences. Additionally, these recommendations are grounded in the practice of other community schools collaborative partners, including Beacon staff and other CBO programs. Although I think this paper will be useful for any school and district engaged in deep collaborative processes with community based organizations, it is will be particularly appropriate for those who are involved with implementing the community schools strategy.

The first two papers of this dissertation laid the groundwork for the recommendations. Therefore, I give the context and background for my research question, summarize both papers, present my recommendations, and finally, offer my call to action. My research question was:

- How do SFUSD community schools, including those operating with and without Beacons, integrate their community based organizations (CBOs) into the leadership structure of their community schools team?

There are a number of reasons why I use the word "equitable" rather than equal. In my experience, it is neither practical nor even possible for $\mathrm{CBO}$ partners to take part in all decisions for a school site. For this paper, equitable means as much as is appropriate, 
fair, or needed relating to the decision making power of non-school staff partners. That is to say that Beacon directors and $\mathrm{CBO}$ partners would be able to contribute less meaningfully to a discussion about restructuring the math department's administrative duties than they would decisions regarding support services and afterschool activities. However, the intention would be that when it is appropriate, as intentionally determined by the principal with the Beacon or $\mathrm{CBO}$ representative during prework, the $\mathrm{CBO}$ voice is heard and valued. Thus, equitable integration of $\mathrm{CBO}$ representation and voice in school leadership structures does not imply equality or sameness in terms of shared decision making. More so, it recognizes, but does not devalue, the differences and dissimilarities of the partners who come from different sectors, and it plays to each partner's strengths (Casey, 2007).

\section{Why I Chose this Research Question}

For me, this journey began when I wrote an article wherein I examined my own position as a Beacon director within the context of the leadership structures of the school where my Beacon Center was located (Hill, 2011). Burton High was selected to pilot the implementation of the community schools model with my program, the Bayview Beacon, as the school's lead agency partner lead agency partner. The principal and I were both new to the concept of community schools. Furthermore, we were both resistant to adding more responsibilities to our already overflowing plates.

Miraculously, through different and somewhat independent processes, the principal and I came to realize that the community schools strategy might complement the work that we do together. It could possibly act as a framework that would help us work together as a cohesive unit. The community schools model stresses building a 
school-CBO collaborative relationship wherein the goals are co-created. That cocreation, a process undertaken by the principal, school leaders, my team, and me sets the foundation for a sense of equity in our team interactions. For example, in the process of co-creating goals, there was space to ascertain what I needed for my program to be successful at the school, as well as to become conscious of what the academic side of the school needed for success. The budding of this deeper connection engendered trust and a sense of belonging between the principal and me, which allowed for more equitable cross sector collaboration.

As the principal and I increasingly collaborated, I noticed that even though we worked well together, it would be easy to replicate the traditional collaboration dynamic that schools and CBO partners have had, particularly if the principal and I did not pay attention to the power dynamics that come into play when a government entity (e.g., a school), partners with a non-profit partner. Researcher, Carolyne Ali-Khan (2010) takes this concept further by asserting that it is not enough to merely acknowledge imbalanced power dynamics. Partners have to try to understand them and how they operate as well. "It requires that the power inequities are not only recognized, but that they are also accompanied by genuine efforts to understand the way these inequities function as they are materially experienced in a given set of conditions" (p.366).

The principal understood this issue before I did, although I was aware of the power imbalance, because that was normal for me as a Beacon representative. In our relationship, I was the person who had to figure out how to shift the Beacon/school paradigm from traditional to transformational. That change happened after the principal made it clear that he actually wanted to hear my input as his lead agency representative, 
and he expected me to sit on his leadership teams and contribute. I had to deconstruct and reconstruct what I thought I knew about partnering with a school an implementer, as being invited to co-create priorities and share my view as a necessary at the table was an usual experience in my two decades as an out-of- school time (OST) professional.

Up until that point, being a great partner had meant making sure the principal had no issues with the support services that my Beacon Center provided. Now, he and the director of the organization that chose Burton to implement the strategy had to explain to me how our new partnership configuration would work. Not only would I be a full member of this collaborative relationship, but the principal wanted me also be included in all of the school's governing mechanisms, including his primary administrative team. Knowing that the principal trusted me enough to fully participate in the school's leadership structure as an partner with a say and vote, was one of the ways that the power dynamics were acknowledged and somewhat equalized. He then institutionalized my role in the partnership by adding me to the school's organizational chart and balanced score card.

The practice of sharing leadership with the school leaders made my recognition of the notion of being a committed partner to Burton, stronger. In those weekly administrative meetings, I was able to bring the issues and ideas that related to my Beacon, or the other $\mathrm{CBO}$ partners, to the highest decision making tables. As a team, we worked on Beacon and school issues because it was understood that Burton concerns were Beacon concerns, and vice versa. Our co-creation process -- sometime formal, sometimes informal -- revolved around meeting each other's immediate and long term needs. From the school needing more credit recovery opportunities for students or food 
for an event, to the Beacon needing money to fund a position or parking spaces closer to the door, as a full member of the admin team, I was kept in the communication loop through formal sit down meetings or emails, texts or passing in the hallway or parking lot. Shared governance and decision making helped to solidify our symbiosis and interdependence.

\section{Summary of Papers}

In Paper 1, I gave the context, research and practical application of the sharing leadership equitably between school and CBO partners. Specifically, I explored the notion of shared leadership practices of schools that are collaborating as a part of implementing the community schools model for principals, community schools coordinators and $\mathrm{CBO}$ partners. In Paper 1, I provided the reader a brief history of the approach in general, then in San Francisco, and finally its history with Beacons.

Because Beacons have a special place in the community schools cannon as a prototype, I used Paper 1 to discuss that history, as well as Beacon history in San Francisco, placing my personal experience, as a Beacon Director implementing the community schools strategy, at the center of that discussion. Paper 1 also put forth a theory of how this new form of collaboration could work between schools and Beacons and/or community partners. This theory described in Figure 1 showed how the components interacted, highlighting shared leadership, the role of power dynamics.

Paper 1 detailed the roles that are important in community schools team's configurations for the collaboration to make sense for all parties involved. In sum, through Paper 1, I gave the reader an overview of some of the players in the San Francisco community schools landscape, along with the issues. Finally, I introduced 
shared leadership, power dynamics and shared agenda, the last of which is a condition of my conceptual framework, known as Collective Impact. My position is that if school district staff and community partners are able to incorporate these three elements into their collaborations, both stakeholders will be more inclined to build durable, highly functioning, cross sector relationships that will help solve educational issues in the long term. Paper 1 is the foundation for Paper 2, which is the paper wherein I undertook a qualitative study to address my research question.

The second paper is designed as a cross case comparison of the praxis of three schools that were in the process of implementing the community schools model. The article I wrote recounted my experience of learning to share leadership and power with the leadership team at Burton High (2011). For the research for Paper 2, The paper formally studies the school/CBO leadership practices at my site that I had originally explored in my 2011 article, while adding the layer of exploring how two other schools integrated $\mathrm{CBO}$ voice into their leadership structures. Those schools were Hillcrest Elementary and Everett Middle School.

One of the most interesting findings was that the paper provided me with a clearer definition of equitable integration and forced me to recognize and critique presumptions around the concept of leadership structures. My study found that leadership structures in schools vary and do not all function the same way. Specifically, I found that Hillcrest Elementary School and Burton High School seem to have a similar leadership structure, whereas the middle school had a tiered system that was more complex. How the leadership is organized could impact the quality of the collaborations between these 
partners, thus it affirmed the importance of my position that partners must define "equitable integration" during prework.

My experience in the simultaneous roles as the Beacon director and a community schools coordinator was extremely challenging. I had had conversations about where Beacons fit within the community schools approach in San Francisco and whether having a Beacon director and a community schools coordinator was duplicative. All three of the schools in my study had different role configurations. Hillcrest's team consisted of the principal, the community schools coordinator and a lead agency partner. Everett's team was the principal, the community schools coordinator, and the lead agency partner was the Beacon director. At Burton, our team was comprised of the principal, and me, a Beacon director who performs some of the community school's coordinator functions. I found that Hillcrest's team's roles were well defined and each member seemed to understand his or her duties to the group. At the same time, the community schools coordinator had other responsibilities, such as raising money and parent engagement, which made her job complicated.

At Burton, as I said, I found it challenging to be a Beacon director full time, and then to add in community schools coordinator duties. The community schools coordinator position was a full time job, in and of itself. To accomplish the agreed upon goals, to manage partnership and to run my Beacon and two other sites at other schools, was basically me doing two full times jobs. In order to succeed, it required superlative time management, which I did not always have. At the same time, because the duties were streamlined, I was a one stop shop, as it related to support services and community 
engagement. I oversaw the afterschool program as well as $\mathrm{CBO}$ engagement. It was a difficult to juggle, but fortunately, there was a fair amount of overlap.

At Everett where they have a community schools coordinator and a Beacon director, the community schools coordinator insisted on more than one occasion that the Beacon director/lead agency partner should be the community schools coordinator as well. In contrast, the Beacon director was adamant that having a community schools coordinator, in addition to her position, was imperative for their configuration. It was very clear at this site that there is a hierarchy associated with these roles. As such, the community schools coordinator has more access to the principal than does the lead agency partner position. The twist about this site was that the Beacon director/lead agency partner was invited to more decision making tables; however, she did not feel that she had the time to go, and delegated that role to the community schools coordinator.

Although all of the configurations had benefits and drawbacks, I was able to better understand how Beacons fit into the community schools scene in San Francisco. Beacons could be the Beacon director/community schools coordinator or the Beacon director/lead agency partner, depending on the needs of the school. I submit that with Everett's leadership structure, it would be difficult for one person to handle all of the duties of the community schools coordinator and run the afterschool and community programs there. I was better equipped to manage both at Burton because our leadership structure is more simplified. Thus, whatever the leadership composition is, it is not something that can be decided without intention. It has to be efficient and effective for all parties involved. 
The final aspect of Paper 2 was examining how developing a shared agenda, acknowledging power dynamics and shared leadership impact the equitable integration of community based organization voice the school leadership structure. Most of the sites had developed co-created or mutually agreed upon goals, which involved identifying a common problem and determining a shared solution that they agreed to work toward. This proved to be an essential part of prework and was a tool for facilitating cohesion among the partners. Two of the three site informants for the study talked about being in alignment with the school's goals with the exception of the Beacon director at Everett. She was fiercely protective of her Beacon Center's identity as connected to, but not absorbed by, the school. Correspondingly, Everett's team was unable to reach consensus on the identifying an issue and a common solution. To the extent that principals, community schools coordinators, Beacon directors and lead agency partners can take the time to develop buy-in and agreed on goals, that helps to put all parties on more equal footing for working together. Burton and Hillcrest were able to take the time and build the trust on their teams the most efficiently. The community school coordinator and principal at Everett mentioned not having enough buy in on several occasions among the team members.

Power dynamics, or the power to make decisions, played different roles at each of the school sites. My presumption was that awareness of power dynamics would break down along the lines of roles on the team. I was surprised to find that the principals at Hillcrest and Everett did not feel that power dynamics played any part in their collaborations. The Burton principal could detect a difference in participation of his CBO partners in the meetings with the school department heads. He attributed this 
disparity to differing agendas, as opposed to power dynamics. Neither the community schools coordinators nor the lead agency partner seemed to notice a power differential in their collaborative relationships. The Beacon directors definitely discerned an imbalance. Since there is literature on the power differential in cross sector collaborations (Kania, Hanleybrown \& Juster, 2014), I wondered why there was so much silence around the issue. I think it is difficult to talk about that subject without seeming negative and disloyal. However the literature says that these dynamics should at least be acknowledged. That power dynamics are neither good, nor bad; they just are. They describe an imbalance in the ability to make decisions or authority to hold partners accountable. For example, the school has the ability to remove a CBO program. At Everett, that Beacon director and her staff that I interviewed were unexpectedly not hired to run the Beacon the following year, without warning or recourse. This is a perfect example of the imbalance of power in these sorts of relationships. Build the trust necessary among partners to truly share leadership can definitely be more complicated when one can summarily dismiss the other.

The final section looked at how the sites shared leadership and decision making. I paid particular attention in this section to how developing a common agenda and looking at power dynamics impacted how community based organization voice was integrated and heard. Principals, Beacon directors, community schools coordinators and lead agency partners can collaborate without sharing leadership. However, sharing decision making power elevates the relationship to a more serious, more committed partnership level, under the community schools approach. 
To varying degrees, all of the school bodies had incorporated either Beacon or lead agency partner representation. Again, the question of equitable integration surfaced. Is there a baseline of decisions that partners should aspire to? At Hillcrest and Burton, the lead agency partner and I are a part of the top leadership decision making bodies. At Everett, there is a multi-layered collaboration structure, and the community schools coordinator attends many of those meetings, but the principal and her assistant principals make most of the high impact decisions. As was mentioned, though the Beacon director is invited, she chose which meetings to prioritize according to her program's needs. Perhaps that striated structure is one of the reasons that the Everett group was the least cohesive of the sites. A mutually agreed upon operational definition of equitable integration might have saved the team deep misunderstandings.

One of the most important factors in this equitable integration of $\mathrm{CBO}$ voice in school leadership structures equation was the practice of sharing leadership. Embedding $\mathrm{CBO}$ representation at decision making tables, allowing these partners to have a voice and a vote, is what helps build the long lasting relationships necessary to survive through conflict and failure, persevering to accomplish the mutually agreed upon goal. After all, the community schools model is more than collaboration. It is about strong relationships between principals, Beacon directors, community schools coordinators and lead agency partners that cultivate enough social capital to help all parties remain focused on solving a goal.

Before I make recommendations, it would be useful to learn more about shared leadership within education, as well as shared leadership policy in the Bay area. The next sections will examine specifically shared leadership in these different contexts. 


\section{Shared Leadership in Education and in the Community Schools Strategy}

As formerly separate groups, such as community based organizations (CBOs) and schools are called upon to combine resources and to collaborate intentionally, there exists an opportunity to develop an inclusive and egalitarian governing structure as well. Shared leadership is one way to purposely embed reciprocity and fairness, particularly for those groups that have not had a voice at school decision making tables in the past. However not all districts mandate that it be practiced, probably as a result of the paucity of information regarding its role in the community schools strategy.

This type of common governance has not been studied extensively as a component of the literature of the community schools strategy although it is mentioned (Blank, Melville \& Shah, 2003; Federation of Community Schools, 2008; San Francisco Public Schools, 2010), along with common visioning. Nonetheless, shared leadership plays a pivotal role as a framework that allows school and communities members to be officially heard at decision making tables. In general, shared leadership models seem to be growing in popularity as tools for promoting school community satisfaction and student achievement in the field of education.

\section{The Bay Area's Current Shared Leadership Policies}

It might be helpful to paint an overall picture of how the Bay Area districts that have been implementing the community schools model are addressing sharing leadership with their CBO partners. Currently in San Francisco, the community schools approach has been embraced by several SFUSD schools. Most of them are the city's lowest performing schools. The majority of these schools have high concentrations of students of color, along with large populations of English learners, high percentages of students 
receiving free and reduced lunch, low graduation and high dropout rates. These students live in some of San Francisco's most impoverished and disadvantaged neighborhoods, such as the Bayview and Mission neighborhoods.

The SFUSD policy on sharing leadership with others (outside of school staff) comes out of the Office of Family and Community Engagement (OFACE). The policy outlines actions and opportunities that engage families as decision makers and leaders. The OFACE seems to define community as parents (SFUSD, 2012). There is hardly any mention at all of $\mathrm{CBO}$ partners and how they should be integrated into decision making. While the lack of $\mathrm{CBO}$ integration is not ideal for shared leadership at the school site, the fact that they include parents is progress.

Community schools in Oakland are similar to those in San Francisco that are practicing the community schools approach. However, Oakland Unified School District has made a concerted effort to engage community partners, including CBOs. As they undertook the strategic planning process to launch their FSCS district, they launched fourteen task forces and held 350 meetings with all their stakeholders, including CBOs. Over 5500 participated in the activities and sessions. They also had a strong emphasis on parent engagement, but not at the expense of the $\mathrm{CBO}$ stakeholders. At the district level, they created several mixed constituency governing bodies. They were even exploring the notion of the Central Office providing regional staffing that would include CBO partners (Oakland Unified School District, 2011)). Ideally, all school districts would have the time and resources to undertake a similar process.

Though both San Francisco and Oakland's district began implementing community schools strategy relatively recently, Oakland is definitely further along in 
terms of creating shared leadership policies that include the $\mathrm{CBO}$ stakeholders. One of the recommendations of this brief is that SFUSD officials analyze Oakland's process for stakeholder buy in, as well as the shared governing bodies that were created, for possible replication in San Francisco.

West Contra Costa Unified School District has recently begun the process of becoming a full service community schools (FSCS) district. In terms of shared leadership opportunities and structures at this point, they have identified shared outcomes targets with the County and other cities in the area. So far the shared leadership bodies are the FSCS Steering Committee, the Community Leadership Teams, and the School Site Teams. All of these groups include participation and representatives of community based organization. Even early in their process, it seems that the West Contra Costa Unified School District understands the importance of sharing leadership and equitable integration.

\section{Barriers to Developing Shared Leadership and the Equitable Integration of CBO Voice}

There are many reasons that the Superintendent or principals and others might hesitate to undertake this process of crafting this policy. The following section will outline 3 key barriers that arose from my research. The need for a definitive district direction is the most serious block, as well as the potentially the richest opportunity.

\section{Barrier \#1: Often a paradigm shift for school culture}

As has been discussed in both previous papers, traditionally, schools call the shots and $\mathrm{CBOs}$ follow. Often in the interest of being efficacious about time, school leadership teams have created goals and plans, and their lead agency or Beacon partner have been brought into the process to help to implement the plans and to reach the 
goals. Traditionally, there has been little equity in decision making. By establishing shared leadership bodies as a policy the principal, community schools coordinator and $\mathrm{CBO}$ representative would be forced to align strategically to solve problem in a way that might be difficult, especially at first. Alternatively, a reciprocal relationship could be developed that had previously never existed. One possibility is that a link, which is hardly ever acknowledged, might gain prominence. That is: school issues are community issues, as community issues are schools issues. Codifying this policy of sharing leadership might actually help to develop truly wrap around services for students and their families. All members of the primary community schools team would have to be ready for the shift. Again, this is another reason for intentional relationship building in the prework stage.

Sharing decision making power with an outside agency can be uncomfortable for all. From my experience and findings in Paper 2, principals are under a lot of pressure to stabilize multiple moving parts. One of the principal's main duties as a leader of a government entity is to maintain the façade of power and control, because chaos could devolve into students underperforming, dissatisfied teachers, and school climate issues.

Each principal from three school sites described their leadership practice as shared. However, the dosage ran a range. For example, the Everett principal said that she and her assistant principals make most of the important decisions and set the core priorities, for the sake of efficiency. She requests stakeholder feedback as needed, and is open to their input. Conversely, the community schools coordinator at Hillcrest hinted that sometimes, there was a little too much decentralization of decision making with partners, which can render sharing leadership less productive. 
This shift to shared decision making is not just difficult for school staff. This shift can be unnerving, as I certainly experienced in my role as the $\mathrm{CBO}$ partner who was accustomed to doing business with the school in ways that were somewhat connected, but not necessarily interconnected. I found that being invited to co-create goals with the school was nerve wracking. It broadened the scope of my job in ways that I later appreciated, but did not expect. It also helped me to understand the reciprocity in my relationship with schools. If I sit on the leadership team of the school, should the principal (or school representative) sit on mine? If we share leadership, should the sharing go just one way? Or worse, will my Beacon be subsumed into Burton and eventually be called the Burton Beacon?

In Paper 2, I found that the Beacon director at Everett also felt this concern of being subsumed. She wanted to make sure that she held on to her autonomous Beacon identity that was always student and community focused. Everett had other priorities, specifically around an academic focus, therefore the Beacon director thought that the best way for her to collaborate with the school was to stay grounded in what she had developed as a Beacon. That way, the principal and community schools coordinator would connect her to the school, and she would remain a touchstone for kids, families, and the Mission community. Conversely, the CBO partner at Hillcrest was clear about his identity as part of the school. He was "Hillcrest." He said that if the lead agency that paid him were to leave Hillcrest, he would not leave with it. He would vet the next organization to make sure it understood the Hillcrest way, and be hired by it. His commitment, loyalty, and allegiance are to the school. CBO enmeshment with the school 
is not as troubling to the Hillcrest lead agency partner as it was to the Beacon director at Everett.

Often, one of the reasons that schools partner with $\mathrm{CBOs}$ is to leverage their ties to the communities outside of the school. That community connection and commitment were aspects of the Beacon Center at Everett that the director was passionate about guarding. My principal once told me that one of the benefits of my position on the leadership team as an outsider is that I always prioritized the perspectives of the noninstructional stakeholders (such as parents and community members). Perhaps when the lead agency partner is fully amalgamated with the school, that benefit is diminished or lost.

In the article I wrote in 2011, I maintain that sharing leadership and decision making power between schools and Beacons is analogous to getting married. Two separate entities merge. However, the healthiest marriages are ones where each individual keeps his or her own identity intact, as well as develops one as a unit. For me, that puts the question of identity to rest.

\section{Barrier \#2: $\quad$ Need for a clearer vision at the District level}

Since the School Improvement Grants (SIG) used to scale the community schools work in San Francisco has sunsetted, and several key champions have moved on, it is difficult to know where the District is going with the community schools strategy. Fortunately, there is the leadership of the district community schools team providing support to those of us who are implementing the community schools strategy on the ground.

Where there once were SIG funds, there are now dollars from the Promise Neighborhoods, a federal program that also leverages community resources to improve 
educational outcome. Additionally, with the recent passing of the Every Student Succeeds Act, there is the opportunity to obtain more funding. However, schools, school districts and $\mathrm{CBO}$ s have to operate as though these monies will eventually evaporate as well. To honor the hard work already done and to support schools that continue to implement this approach with or without specific funding, there should be an effort to shore up this policy for San Francisco schools. This policy should ensure that CBO representation is written into leadership structures at school sites, whether there is community schools money or not. A clearer and stronger mandate from the central office would signal to the schools and CBO partners in the SFUSD (and beyond) the importance and maybe the permanence of the shared leadership practice.

\section{Barrier \#3: Unchecked power dynamics}

As has been discussed in Papers 1 and 2, unacknowledged power dynamics can derail the school-CBO partnership, particularly as it relates to sharing leadership. The power to make decisions in cross sector collaborations is often weighted more heavily on one partner than the other. Mistrust and disconnection can result when this dynamic is not recognized or actively mitigated.

\section{The Prognosis for the Community Schools Model at SFUSD}

In San Francisco, if and when the money dries up for the community schools model implementation, it is hard to say what will happen with this policy. Without dedicated dollars, perhaps the impetus for fine-tuning this model will diminish as well. However, inasmuch as there are still several schools who are implementing the community schools strategy in San Francisco, it behooves the District continue the small learning communities that have been formed in the incubators to continue creating this 
policy. Particularly when schools will not have the extra funding, having a policy wherein schools and CBOs share leadership could mean the difference between all the excellent partnerships disappearing or the work continuing seamlessly because all the stakeholders have built the durable relationships that are focused on continuing to solve problems.

\section{Recommendations}

The work for this issue rests with the district, such as the Superintendent or the Director of Community Schools, and principals, at the site level. However, Beacon directors and lead agency partners will be integral to supporting these policies on the ground. An official policy has to be developed that would institutionalize s shared leadership practice within the governing structures of schools implementing the community schools strategy in San Francisco, especially. I would recommend that a team be convened to study the lessons learned from Oakland, so as to build on readily available data and experience. I submit the following recommendations for immediate action:

Recommendation \#1: Define a policy that institutionalizes the equitable integration of community based organization representation in leadership structures

This recommendation is essential defining a clearer vision at district level. Even though Marty Blank and other community schools leaders say "if you've seen one community school, you've seen one community school," there are ways to ensure that the $\mathrm{CBO}$ integration remains the similar across all the schools implementing the model. In the same way that schools have a School Site Council, which oversees the budget for the school, there can be can be a mandate that all schools adopting the community schools approach should have a community schools team that would include the principal, the 
Beacon director or community schools coordinator, or the lead agency partner/Beacon director. This team should meet weekly, having co-created or mutually agreed upon goals, and a plan of action with agreed upon steps.

This policy should clearly lay out the process for developing shared leadership collaborations that all schools implementing model should follow. One of the issues that surfaced in the three sites was that all of the leadership teams were basically making it up as we went along - in other words, building the plane and flying it at the same time. I recommend that the district adopt the Collective Impact framework (Kania \& Kramer, 2011), as its focus is on the people who will be collaborating. This framework lays out five conditions for collaboration and is performance-focused. These five conditions are: common agenda, shared measurement, mutually reinforcing activities, continuous communication and backbone organization. I eventually focused on shared agenda in the previous papers.

The district also needs to define and make use of the term "equitable" as it relates to how CBOs and schools share leadership. Additionally, I suggest that you explicitly name CBOs in any policy that addresses shared leadership. In Paper 2, I saw that different schools have various levels of leadership and decision making bodies. This policy should explicitly name a $\mathrm{CBO}$ program such as Beacon, so that they will always be asked to be at the shared leadership and decision making tables. The CBO partner may not always accept, as was the case for Everett Middle School described in Paper 2, but the policy should ensure that one $\mathrm{CBO}$ partner is present. As a result of being explicit, there is no guesswork because the district leadership has mandated that a $\mathrm{CBO}$ be a part of the process. 
Recommendation \#2: Mandate prework wherein goals are co-created or mutually agreed upon.

Building a solid foundation from which to collaborate and share leadership is imperative. It takes at least two things: time and effort. Oakland Unified took several months to plan before putting any of their efforts into action. SFUSD had to hit the ground running when it started implementing the community strategy because the SIG funds were three year grants, and by the time all the coordinators were hired, half the first year had expired. Schools had intentional and dedicated time to discuss what it might take to enact such a policy with community schools teams about once per month at the incubator meetings, discussed in Paper 1.

Prework should include co-created measureable goals. Further, this collaboration should be performance based. That is not to say that the school or CBO partner is given a report card. In this stage, enough social capital and trust should be built, such that there is a commitment to reaching the shared goal together. Remember, the commitment in these partnerships is like marriages (Hill, 2011). When a goal is not reached, the partners should not rush to separate. Instead, their commitment means they will take the time to evaluate, reassess, and to build on existing social capital within each partner's capacities, to continue working toward the shared goal.

Certainly, it would be a lot of work to try to develop and implement the shared leadership policy. It seems a daunting, yet necessary, task to push this effort forward. I recommend that SFUSD build these shared leadership coalitions using the Collective Impact framework, for any school implementing the community schools model. The time needed to develop trust and buy-in would ideally happen in the prework stage. That would indicate that there actually should be time designated at the beginning of each 
principal-CBO lead agency partnership to create a plan and goals, in addition to the decide if and on which decision making body this partner will participate. Both Burton and Hillcrest's primary community schools teams, including the Beacon and lead agency partner, took a lot of time to build relationships with each other that endure over the long run.

Unfortunately at Everett, the principal, community schools coordinator and Beacon director mentioned not having enough time several times. The principal was new; the community schools coordinator had several layers of.responsibility including tight coordination of the school's partnerships, but also direct service for approximately 30 $40 \%$ of her time. As a district employee, her community schools coordinator responsibilities included weekly lunch duty, pushing into classroom to help with students, and taking students out of classrooms. Similarly, the Beacon director felt that she did not have the time or capacity to sit in more meetings, especially since she felt that her input was collected and transmitted to the governing bodies by the community schools coordinator

At the start of this school year, the Everett leadership team entered into a rebuilding stage, which could have been a time to recalibrate and recommit to making sure that all parties felt included and focused on a co-created or mutually agreed upon goals. Unfortunately, without a designated period to focus on their relationships, the school year started, and the frantic pace of dealing with issues and reacting to crises meant that a plan did not unfold within the academic year. Thus, the community schools coordinator did not feel as connected to the larger picture as she did when she had more access and time with the previous principal. This situation illustrates the notion that 
prework, with all partners present, is necessary at the beginning of a new cycle or when CS team has been destabilized and needs to rejuvenate itself. Additionally, because the Beacon director wanted to play more of a tacitly connected role, as the lead agency partner, and the principal and community schools coordinator wanted her to be more involved with meetings, a serious disconnect might have been avoided had there been more time dedicated to hashing out exactly how their configuration could work to allow them to address their mutually agreed upon goals and solutions.

Recommendation \#3: Focus on principals. Principals need a principal training program to learn the specifics of sharing leadership with their $C B O$ or Beacon partners, preferably by other principals

Paper 2 showed what a pivotal role principals play in the success of how the community schools model and the sharing of leadership can be embraced at his or her school. As the head of the school, when principals are onboard, their commitment radiates out to the entire team, and indeed all the school community. If there are enough resources, the community schools team is more innovative, creative and committed, which was the case when Hillcrest had money for planning in Paper 2. A training program for principals would be extremely useful. It might be designed in the following way: one track that trains principals who are new to the concept of sharing leadership and the community schools strategy, a second track that refreshes principals with 1-3 years of experience, and a track for seasoned principals. Such a program would need some commitment from the district and so I recommend a 2-day, 16 hour workshop. Below is a sample program: 
Table 2. Sample Principal Training Program

\begin{tabular}{|c|c|c|c|}
\hline & $\begin{array}{l}\text { FLEDGLING } \\
0-1 \text { YEARS }\end{array}$ & $\begin{array}{l}\text { RISING } \\
\text { 1-3 YEARS }\end{array}$ & $\begin{array}{l}\text { SEASONED } \\
3+\text { YEARS }\end{array}$ \\
\hline Intro & $\begin{array}{l}\text { Community schools } \\
\text { advocate }\end{array}$ & Principal & $\begin{array}{l}\text { Community schools } \\
\text { scholar }\end{array}$ \\
\hline $\begin{array}{l}\text { Workshop } \\
\text { A }\end{array}$ & $\begin{array}{l}\text { What is the community } \\
\text { schools strategy? } \\
\text { (receive toolkit) }\end{array}$ & $\begin{array}{l}\text { Shared leadership } \\
\text { w/CBO; } \\
\text { community } \\
\text { schools team }\end{array}$ & $\begin{array}{l}\text { Checkup: } \\
\text { Collective Impact }\end{array}$ \\
\hline $\begin{array}{l}\text { Workshop } \\
\text { B }\end{array}$ & Shared agenda & $\begin{array}{l}\text { Common } \\
\text { assessment and } \\
\text { evaluation tools }\end{array}$ & Funding \\
\hline $\begin{array}{l}\text { Workshop } \\
\text { C }\end{array}$ & Communication & $\begin{array}{l}\text { Cultivating buy-in } \\
\text { of teachers } \\
\text { parents and } \\
\text { students }\end{array}$ & $\begin{array}{l}\text { Shared leadership } \\
\text { w/ CBO; CS team }\end{array}$ \\
\hline $\begin{array}{l}\text { Workshop } \\
\text { D }\end{array}$ & $\begin{array}{l}\text { Shared leadership } \\
\text { w/CBO; CS team }\end{array}$ & $\begin{array}{l}\text { Checkup: } \\
\text { Collective Impact }\end{array}$ & $\begin{array}{l}\text { CS state of the } \\
\text { community schools } \\
\text { strategy Union - what is } \\
\text { going on in the field? }\end{array}$ \\
\hline
\end{tabular}

The goal would be to immerse principals in the concepts and in community. They would understand the theory, practice, and take the time to build their commitment to the strategy. The last part of the final day would bring the principals, community schools coordinator, Beacon director or $\mathrm{CBO}$ partner together for team building and planning.

This professional development training program would be part of their prework.

There could be a tiered system of principal coaches and follow up could be provided through adding 30 minutes to their regular principal meeting. Materials would be available online as well, such as a website to share resources and ideas and discussion boards for coaches to communicate with their mentees. A robust online site would minimize the necessity for face time, yet still provide support. 
The principals in my study could have benefitted from a uniform training. They took disparate paths to understanding that principals can embrace the community schools model and shared leadership. Both the Hillcrest and Burton principals seemed to be already predisposed to sharing leadership. The community schools coordinator at Hillcrest noted that Hillcrest had a long history of sharing leadership, even before they started implementing the community schools model. The flattened structure, wherein the principal distributed decision making to various stakeholders, began with the previous principal. Perhaps the new principal at Everett could have used help from other principals at a dedicated two day workshop before school the school year began, as well as ongoing technical assistance. It seemed that she and the Beacon director were both strong committed leaders who were passionate about students and families. They might have made a powerful leadership team, if they had started the year seeing eye to eye.

Recommendation \#4: Beacons and the district's community schools team should be intentional about the most efficient ways to share leadership and resources

One point that surfaced in Papers 1 and 2 was that it is important to set up Beacons and school shared leadership to succeed. While historically, Beaçons were a prototype for community schools work, not all Beacons under the San Francisco Beacon Initiative (SFBI) are equipped to accomplish the tasks required of a Beacon director and community schools coordinator. When a Beacon director and principal decide to share leadership as a community school, the Executive Director of the San Francisco Beacon Initiative (SFBI), and Dr. Hayin Kim, the Community Schools Director for SFUSD, should have meetings with them to discuss and manage expectations, set preliminary goals, troubleshoot any glaring issues, and make a plan that would take into account the needs of the school as well as the needs of the Beacon director. There should be 
handouts and a turnkey toolkit for how to establish routines, structures, and relationships for sharing leadership. The toolkit will start the incubation period and help the new team set goals for 30, 60, 90 and 365 days. There should be check-ins with community schools team at each of those points. The community schools team and SFBI will play that backbone organization, which is a critical roles in the Collective Impact framework, as its function support, sustain and help scale the work.

Additionally, when a Beacon is acting as the lead agency partner, working with a community schools coordinator, it is still imperative to make sure that all parties have common perceptions and expectations around the way they will work together, common goals and solutions, measurements of success, and mandatory meetings. When a school that has a Beacon Center decides to become a community school, the way that the Beacon Center has functioned will likely change. Focused collaboration, alignment, integration and sharing leadership are important components of the community schools strategy, and it is essential that the Beacon director be a fully present and participating partner in accordance with whatever agreements s/he makes.

Recommendation \#5: Common goal plus shared governance equals shared responsibility \& investment

Shared leadership in coalitions helps to build the team atmosphere that facilitates groups working together through victories and setbacks. That is the salient idea related to the community schools model. Collaboration is important. Sharing leadership is critical. By themselves, they are much less effective. Again and again, the literature said "we can't do it alone." Those strategies will not elicit the transformative results that the community schools strategy promises alone. The long term goal is to cultivate the strong 
relationships between principals, community schools coordinators, Beacon directors and lead agency partners that remain functional and focused on the ultimate goals, even in the face of challenges and failure. Conceptually, the deeper the connection grows, the more cohesive and committed the team, the easier it would be to continue working toward and accomplishing common goals.

Recommendation \#6: A say in how blended money, staff and time resources fill gaps could translate into empowered communities

Having the Beacons and $\mathrm{CBO}$ representing community voice could cultivate this same kind of leadership in the surrounding communities. One of the advantages of having me on the leadership team is that the Bayview $\mathrm{Y}$ is an organization that has been rooted in the Bayview district for decades. I am on the leadership teams at the $\mathrm{Y}$, as well as at school, so I am able to support community schools concepts in the community, and vice versa. Sharing leadership is very important at meetings in the community precisely for the reasons discussed here. It is essential to seek out voices that are not normally heard and encourage them to participate in neighborhood councils.

\section{Implications for Future Study}

My study surfaced the need for more investigation for several rich subjects. For example, I chose to focus on only one of the Collective Impact framework conditions. There are four other conditions that should be studied. I would start with questions such as: What is the role and importance of backbone organization in community schools? Or what factors facilitate and hinder continuous communication?

Trust is another subject that should be studied more in-depth, especially within the context of the community schools model. A question might be what are the best 
practices for addressing power in cross sector collaboration? Also, how do partners build trust in less than amicable collaborative environments?

A researcher could take a deeper dive into how shared leadership and equitable integration of $\mathrm{CBO}$ voice actually functions by asking questions such as: what roles do other stakeholders, such as students and parents function in a shared leadership structures? What are the factors or elements that indicate that all partners are feeling heard and respected while sharing leadership?

A research question around individual identity in collaborations would be beneficial. For example,, "how do organizations maintain their identity and independence as they forge deep collaborative relationships?". Additionally, I've already mentioned that it would be helpful to study specifically the relationship at schools that have a Beacon director and a community schools coordinator. A question might be what conditions must be present to facilitate healthy and productive collaborations between the Beacon director and the school staff?

\section{Conclusion}

This is a pivotal moment in education in San Francisco. The District has acknowledged that schools cannot solve the problems they face alone, and neither can CBOs. Leveraging our resources and efforts would allow us both to work smarter and not harder. Sharing leadership is a part of that strategy because it facilitates stronger partnerships between schools and nonprofit entities, and allows them to work together to achieve a common goal. As schools and CBOs collaborate more effectively, the district should move to supporting the partners to move from open-ended collaboration to shared 
leadership, as that is the next level of commitment. What is crucial in this move is that the schools and $\mathrm{CBO}$ programs develop shared agendas and are mindful of power dynamics, as they conscientiously and equitably integrate nonprofit partner representation in decision making processes and structures.

It can be done, especially when schools and CBOs are implementing the community schools approach. This strategy mandates deep and focused collaborative partnerships. Effective collaboration, alone, is usually messy and uncomfortable at least for a while. It takes patience and commitment to both goals and also to the relationship. As is the case with any committed relationship, trust and a strong feeling of interconnectedness are key. School shared leadership practices that consciously integrate CBO voice forge a deeper link between partners, as was seen in Papers 1 and 2.

Just as the School Site Council is mandatory at each site, shared leadership practices should be institutionalized at every level of leadership at a school, especially if the school is implementing the community schools approach. There should be trainings, particularly for principals, to help them understand the particulars of sharing decision making power with an outside agency. CBO programs, including Beacons should also be trained for this very specific and often new facet of their job. All partners have to understand the reciprocal nature of this level of collaboration, and commit to building trust, buy-in, and mutual respect for it to have a chance at serving the purpose that it is intended to serve. The purpose of sharing leadership is to build durable relationships among the people who work with the students and their families, such that they make long term commitments to work on entrenched problems that are barriers to student success. 


\section{References}

Ali-Khan, C. (June 01, 2010). Sharing a disparate landscape. Cultural studies of science education, 5(2), 361-371.

Blank, M. J., Melaville, A., \& Shah, B. P. (2003). Making the difference: Research and practice in community schools. Washington, DC : Coalition for Community Schools.

Bryk, A. S. (April 01, 2010). Organizing Schools for Improvement. Phi Delta Kappan, 91(7), 23-30.

Bryson, J., Crosby, B., \& Stone, M. (2006). The design and implementation of crosssector collaborations: propositions from the literature. Public Administration Review, 66(s1), 44-55. http://dx.doi.org/10.1111/j.1540-62.10.2006.00665.x

Bryson, J., Crosby, B., \& Stone, M., Saunoi-Sandgren, S. (2009). Designing and managing cross-sector collaboration. The IBM Center for the Business of Government, 66(s1), 44-55. http://dx.doi.org/10.1111/1.1540-6210.2006.00665.x

Business Higher Education Forum,. (2009). Improving education through collaboration (pp. 1-17).

Dorado, S., Giles, D., \& Welch, T. (January 01, 2009). Delegation of coordination and outcomes in cross-sector partnerships. Nonprofit and Voluntary Sector Quarterly, 38(3), 368-391.

Dryfoos, J., \& Maguire, S. (2002). Inside full-service community schools. Thousand Oaks, CA: Corwin Press. 
Epstein, J. L. (2005). A case study of the partnership schools comprehensive school reform (CSR) model. Elementary School Journal, 106(2), 151.

Epstein, J. L., \& Sanders, M. G. (2006). Prospects for Change: Preparing Educators for School, Family, and Community Partnerships. Peabody Journal of Education, 81(2), 81-120.

Epstein, J. L. (January 01, 2008). Improving family and community involvement in secondary schools - New approaches make partnership programs possible. The Education Digest, 73(6), 9.

Harris, A. (2005). Reflections on distributed leadership. Management in Education, 19(2), 10-12.

Hill, C (2011). Powersharing: Building school/CBO relationships. Afterschool Matters, $14,48-52$.

Kania, J., Hanleybrown, F., \& Juster, J. (2014). Essential mindset shifts for collective impact. Winter 2011. p. 36-41.[3]Stanford Social Innovation Review.4-7.

Kania, J \& Kramer, M. (2011). Collective impact. Stanford Social Innovation Review. Winter 2011. p. 36-41.[3].

Kocolowski, M. (2010). Shared leadership: Is it time for a change? Emerging Leadership Journeys, 3(1), 22-32.

Lambert, L. (2006). Lasting leadership: Study of high leadership capacity schools. Educational Forum, The, 70(3), 238-254.

MacNeil, A, McClanahan, A (2005). Shared leadership. Connexions, Version 1.2

Oakland Unified School District (2011, June) Community Schools, thriving students. Retrieved from Oakland Unified School District 
website: http:/www.thrivingstudents.org/sites/default/files/Community-SchoolsThriving-Students-Strategic-Plan.pdf

Ryan, M.J. (2014). Power dynamics in collective impact. Stanford Social Innovation Review.15-18.

Sanders, M. G. (2005). Building bridges toward excellence: Community involvement in high schools. High School Journal, 88(3), 1-9

San Francisco Unified School District (2012, May 8). Teacher layoffs precede, district projects $\$ 83$ million deficit. Retrieved from San Francisco Unified School District website: http:/www.sfusd.edu/en/news/current-news/2012-news$\underline{\text { archive/05/teacher-layoffs-proceed,-district-projects-\$83-million-deficit.html }}$

Selsky, J. \& Parker, B (2005). Cross-sector partnerships to address social issues. Journal of Management, 31(6), 849-873

Warren, M. R. (2005). Communities and schools: A new view of urban education reform. Harvard Educational Review, 75(2), 133-173.

Yaron, J. (2009). Shared Leadership - Practice and perceptions of teachers in a virtual community. Unpublished dissertation, Hebrew University. 
(+) Facilitator

Prework:

Shared Agenda

Increased:

- Trust

- Connection

- Cohesion

- Interdependence
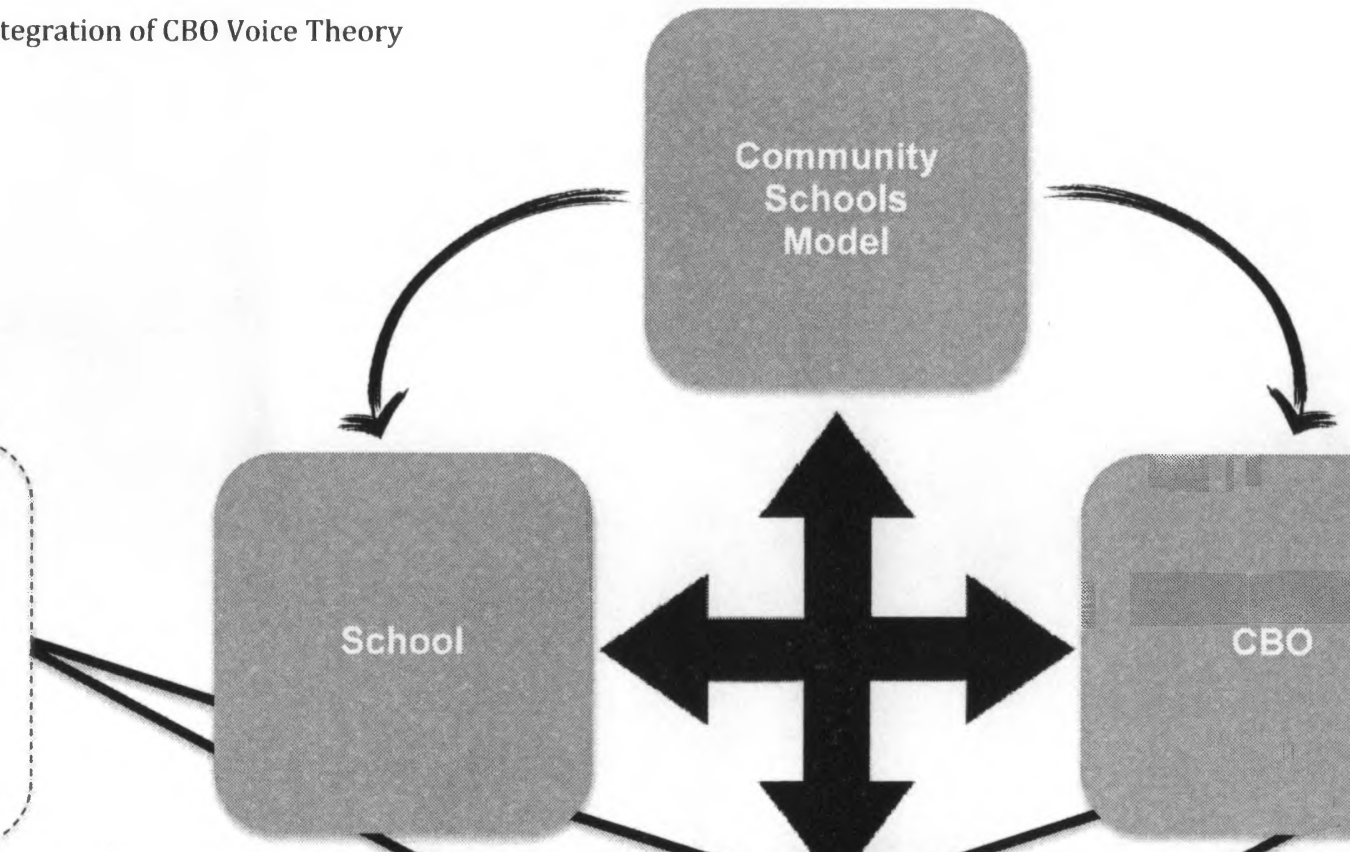

\section{(-) Hindrance}

Unchecked Power Dynamics

Increased:

- Mistrust

- Disconnection

- Incoherence

- Isolation

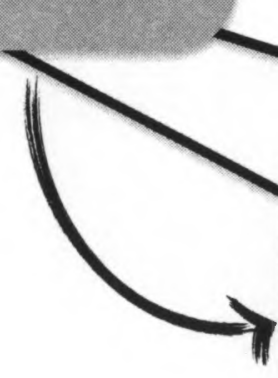

Shared Leadership
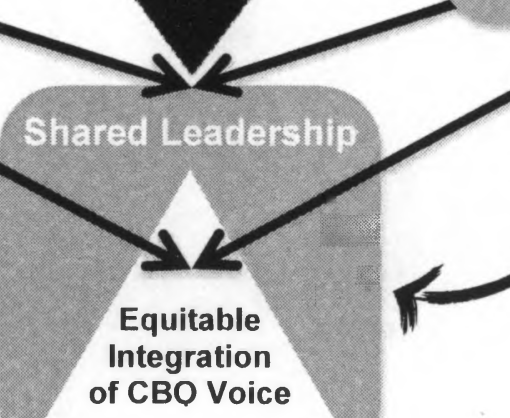


\section{Appendix A - Interview Questions}

1. How do you share leadership responsibilities with your school/CBO partner?

2. Define the community schools model?

3. What are the main leadership structures in your school and how are your partners/organization integrated?

4. Describes 3 benefits and challenges of integrating CBO partners in school leadership structures.

5. Which decisions can you make together? Which separately?

6. What role do power dynamics play in decision making and sharing leadership?

7. How important is shared accountability?

8. How do you evaluate this relationship?

9. What is the process for making improvement?

10. What deliberate or indirect efforts are made to build trust? 
Appëndix B - Informed Consent

Informed Consent to Participate in a Research Study

Putting the Community in Community Schools: A Qualitative Study

\section{PURPOSE AND BACKGROUND}

The purpose of this qualitative study is to highlight practices that meaningfully and equitably integrate community participation in leadership at schools implementing the community schools model (CSM).

The researcher, Carol Hill, is the Director of the Bayview Beacon and a doctoral student in Educational Leadership at San Francisco State University.

You are being asked to participate in this study because you are enrolled leader, scholar, principal, community schools coordinator or community partners in the schoolcommunity partnerships or community schools model movements.

\section{$\underline{\text { PROCEDURES }}$}

If you agree to participate in this research study, the following will occur:

a) You will be interviewed for between 30-60 minutes by the researcher.

b) You may be invited to participate in a follow-up interview no longer than 30 minutes.

c) Interviews will be scheduled at your convenience in person, by phone or via Skype at your convenience. Interviews will take place in the researcher's office at Burton High School or on the campus of the case study sites.

\section{RISKS}

There is a risk of loss of privacy. However, no names or identities will be used in any published reports of the research without express permission of the subject in the second study. Only the researcher will have access to the research data. Any names or identifying information of individual participants will be changed or omitted in the third study.

\section{CONFIDENTIALITY}

The research data will be kept in a secure location, and only the researcher will have access to the data. At the conclusion of the study, questionnaire data will be stored for one year following the completion of the study then destroyed. 


\section{DIRECT BENEFITS}

There will be no direct benefits to the participant.

\section{COSTS}

There will be no cost to you for participating in this research.

\section{COMPENSATION}

There will be no compensation for participating in this research.

\section{ALTERNATIVES}

The alternative is not to participate in the research.

\section{OUESTIONS}

You have spoken with Carol Hill about this study and have had your questions answered. If you have any further questions about the study, you may contact the researcher by email at crhill@mail.sfsu.edu.

Questions about your rights as a study participant, or comments or complaints about the study, may also be addressed to the San Francisco State University Office for the Protection of Human Subjects at 415-338-1093 or protocol@sfsu.edu.

\section{CONSENT}

You have been given a copy of this consent form to keep.

PARTICIPATION IN THIS RESEARCH IS VOLUNTARY. You are free to decline to participate in this research study, or to withdraw your participation at any point, without penalty.

Signature

Research Participant

Date:

Signature

Date: 